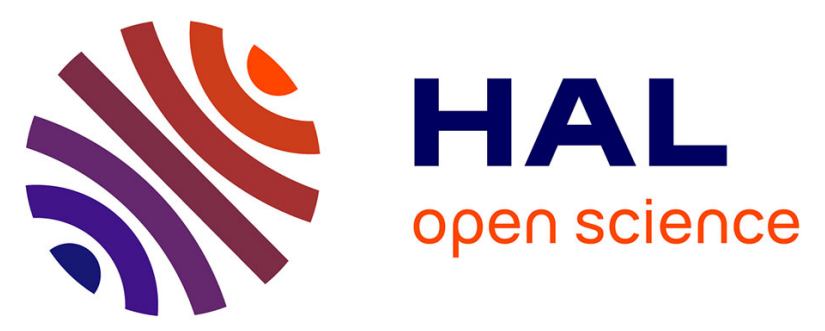

\title{
Selective changes in cytosolic $\beta$-adrenergic cAMP signals and L-type Calcium Channel regulation by Phosphodiesterases during cardiac hypertrophy
}

\author{
Aniella Abi-Gerges, Liliana Castro, Jérôme Leroy, Valérie Domergue, \\ Rodolphe Fischmeister, Grégoire Vandecasteele
}

\section{To cite this version:}

Aniella Abi-Gerges, Liliana Castro, Jérôme Leroy, Valérie Domergue, Rodolphe Fischmeister, et al.. Selective changes in cytosolic $\beta$-adrenergic cAMP signals and L-type Calcium Channel regulation by Phosphodiesterases during cardiac hypertrophy. Journal of Molecular and Cellular Cardiology, 2021, 150, pp.109-121. 10.1016/j.yjmcc.2020.10.011 . hal-03005842

\section{HAL Id: hal-03005842 https://hal.science/hal-03005842}

Submitted on 14 Nov 2020

HAL is a multi-disciplinary open access archive for the deposit and dissemination of scientific research documents, whether they are published or not. The documents may come from teaching and research institutions in France or abroad, or from public or private research centers.
L'archive ouverte pluridisciplinaire HAL, est destinée au dépôt et à la diffusion de documents scientifiques de niveau recherche, publiés ou non, émanant des établissements d'enseignement et de recherche français ou étrangers, des laboratoires publics ou privés. 


\title{
Selective Changes in Cytosolic $\beta$-adrenergic cAMP Signals and L-Type Calcium Channel Regulation by Phosphodiesterases during Cardiac Hypertrophy
}

\author{
Aniella Abi-Gerges ${ }^{1}$, Liliana Castro², Jérôme Leroy ${ }^{3}$, Valérie Domergue ${ }^{4}$, Rodolphe Fischmeister ${ }^{3}$, \\ Grégoire Vandecasteele ${ }^{3}$ \\ ${ }^{1}$ Gilbert and Rose-Marie Chagoury School of Medicine, Lebanese American University, P.O. Box \\ 36, Byblos, Lebanon. \\ ${ }^{2}$ Sorbonne Université, CNRS, Biological Adaptation and Ageing, 75005, Paris, France. \\ ${ }^{3}$ Signaling and Cardiovascular Pathophysiology, INSERM, UMR-S1180, Université Paris-Saclay, 92296 \\ Châtenay-Malabry, France. \\ ${ }^{4}$ UMS-IPSIT, INSERM, Université Paris-Saclay, 92296 Châtenay-Malabry, France.
}

Running title: Phosphodiesterase regulation of cAMP and $I_{\mathrm{Ca}, \mathrm{L}}$ during cardiac hypertrophy

Correspondence to:

Dr Grégoire VANDECASTEELE

INSERM UMR-S1180

Université Paris-Saclay

Faculté de Pharmacie

5, Rue J.-B. Clément

F-92296 Châtenay-Malabry Cedex

France

Tel. 33-1-46 835717

Fax 33-1-46 835475

E-mail: gregoire.vandecasteele@ universite-paris-saclay.fr 


\section{ABSTRACT}

Background In cardiomyocytes, phosphodiesterases (PDEs) type 3 and 4 are the predominant enzymes that degrade cAMP generated by $\beta$-adrenergic receptors ( $\beta$-ARs), impacting notably the regulation of the L-type $\mathrm{Ca}^{2+}$ current $\left(I_{\mathrm{Ca}, \mathrm{L}}\right)$. Cardiac hypertrophy $(\mathrm{CH})$ is accompanied by a reduction in PDE3 and PDE4, however, whether this affects the dynamic regulation of cytosolic cAMP and $I_{\mathrm{Ca}, \mathrm{L}}$ is not known.

Methods and Results $\mathrm{CH}$ was induced in rats by thoracic aortic banding over a time period of five weeks and was confirmed by anatomical measurements. Left ventricular myocytes (LVMs) were isolated from $\mathrm{CH}$ and sham-operated (SHAM) rats and transduced with an adenovirus encoding a Förster resonance energy transfer (FRET)-based cAMP biosensor or subjected to the whole-cell configuration of the patch-clamp technique to measure $I_{\mathrm{Ca}, \mathrm{L}}$. Aortic stenosis resulted in a $46 \%$ increase in heart weight to body weight ratio in $\mathrm{CH}$ compared to SHAM. In SHAM and CH LVMs, a short isoprenaline stimulation (Iso, $100 \mathrm{nM}, 15 \mathrm{~s}$ ) elicited a similar transient increase in cAMP with a half decay time ( $\left.\mathrm{t}_{1 / 2 \text { off }}\right)$ of $\sim 50 \mathrm{~s}$. In both groups, PDE4 inhibition with Ro-201724 (10 $\left.\mu \mathrm{M}\right)$ markedly potentiated the amplitude and slowed the decline of the cAMP transient, this latter effect being more pronounced in SHAM $\left(\mathrm{t}_{1 / 2 \text { off }} \sim 250 \mathrm{~s}\right)$ than in $\mathrm{CH}\left(\mathrm{t}_{1 / 2 \mathrm{off}} \sim 150 \mathrm{~s}, P<0.01\right)$. In contrast, PDE3 inhibition with cilostamide $(1 \mu \mathrm{M})$ had no effect on the amplitude of the cAMP transient and a minimal effect on its recovery in SHAM, whereas it potentiated the amplitude and slowed the decay in $\mathrm{CH}\left(\mathrm{t}_{1 / 2 \text { off }} \sim 80 \mathrm{~s}\right)$. Iso pulse stimulation also elicited a similar transient increase in $I_{\mathrm{Ca}, \mathrm{L}}$ in $\mathrm{SHAM}$ and $\mathrm{CH}$, although the duration of the rising phase was delayed in $\mathrm{CH}$. Inhibition of PDE3 or PDE4 potentiated $I_{\mathrm{Ca}, \mathrm{L}}$ amplitude in SHAM but not in $\mathrm{CH}$. Besides, while only PDE4 inhibition slowed down the decline of $I_{\mathrm{Ca}, \mathrm{L}}$ in SHAM, both PDE3 and PDE4 contributed in $\mathrm{CH}$. 
Conclusion These results identify selective alterations in cytosolic cAMP and $I_{\mathrm{Ca}, \mathrm{L}}$ regulation by PDE3 and PDE4 in $\mathrm{CH}$, and show that the balance between PDE3 and PDE4 for the regulation of $\beta$-AR responses is shifted toward PDE3 during $\mathrm{CH}$.

\section{KEYWORDS}

Cardiac hypertrophy - Cyclic nucleotide phosphodiesterases - cAMP - L-type $\mathrm{Ca}^{2+}$ current. 


\section{Introduction}

The intracellular second messenger cAMP modulates a myriad of processes in the cardiovascular system, from short-term regulation of contraction and relaxation to long-term effects on growth and survival. In the heart, an elevation of cAMP, particularly through $\beta$ adrenergic receptor $(\beta-A R)$ stimulation, exerts positive inotropic and lusitropic effects by activating the cAMP-dependent protein kinase (PKA) which regulates the main components of the excitation-contraction coupling (ECC) process. These include sarcolemmal L-type $\mathrm{Ca}^{2+}$ channels (LTCCs) which underlie the L-type $\mathrm{Ca}^{2+}$ current $\left(I_{\mathrm{Ca}, \mathrm{L}}\right)$, ryanodine receptors $(\mathrm{RyR} 2)$ responsible for $\mathrm{Ca}^{2+}$ release from the sarcoplasmic reticulum (SR), the $\mathrm{SR}^{2+}{ }^{2+}$-ATPase (SERCA2) inhibitor phospholamban (PLB), and the myofilament proteins troponin I and myosin-binding protein C [1].

The intracellular cAMP levels result from the equilibrium between its synthesis by adenylyl cyclases (AC) and its degradation by cyclic nucleotide phosphodiesterases (PDEs). Five PDE families can degrade cAMP in the heart: PDE1, which is activated by $\mathrm{Ca}^{2+}$-calmodulin; PDE2, which is stimulated by cGMP; PDE3, which is inhibited by cGMP; PDE4 which is activated by PKA; and PDE8. In cardiomyocytes, the PDE3 and PDE4 families prevail to hydrolyze cAMP and regulate ECC. The respective contribution of these two families varies depending on the species, the concentration of cAMP, and the subcellular compartment under investigation [2]. In rats and mice, PDE4 predominates to hydrolyze cAMP generated by $\beta$-AR stimulation in the cytosol and at the plasma membrane and to regulate $I_{\mathrm{Ca}, \mathrm{L}}[3-6]$. However, when PDE4 is inhibited, PDE3 becomes predominant to degrade cAMP, and to regulate $I_{\mathrm{Ca}, \mathrm{L}}[5]$. Further studies identified the association of specific isoforms of these two PDE families with the main actors of cardiac ECC: PDE3A1 and PDE4D with SERCA2/PLB[7-9], PDE4D with RyR2[10], and PDE4B with LTCC [6]. 
Impairment of cAMP-mediated signaling is a hallmark of pathological cardiac hypertrophy $(\mathrm{CH})$ and heart failure (HF). The main changes include a decreased $\beta_{1}$-AR density, an uncoupling of $\beta$-ARs from $G_{s}$ proteins, an increased $G_{i}$ expression and an increased G-protein-coupled receptor kinase (GRK) activity [11]. In addition, $\beta_{2}$-ARs were reported to be redistributed from Ttubules to peripheral sarcolemma in HF [12]. Downstream of cAMP synthesis, contrasted results were obtained regarding PDE modifications in human and in various animal models of $\mathrm{CH}$ and $\mathrm{HF}[2]$. Although a majority of studies found a reduction in PDE3 [13-16] and in PDE4 [10, 17] some studies found no change in PDE3 [18-20] or even an increase in PDE3 and/or PDE4 [21-23]. In the case of PDE3, some of this heterogeneity could be linked to the existence of a polymorphism in the promoter region of the PDE3A gene that regulates transcription by cAMP, for example in response to treatment with PDE3 inhibitors [24].

Deregulation of cAMP in specific microdomains due to genetic or pharmacological impairment of PDEs can cause arrhythmias and HF $[6,10,23,25,26]$. Therefore, an obvious question is whether $\mathrm{CH}$ and $\mathrm{HF}$ are associated with specific disturbances in local cAMP microdomains differentially regulated by PDEs. Recent studies using transgenic mice expressing cAMP biosensors targeted to the plasma membrane and the $\mathrm{SR}$ have suggested that $\mathrm{CH}$ is accompanied by a spatial redistribution of PDEs leading to disturbed cAMP compartmentation [27-29].

In a rat model of compensated $\mathrm{CH}$ induced by aortic stenosis, we have shown previously that the expression and the activity of PDE3 and PDE4 were decreased, and that this was associated with a less stringent control of $\beta$-AR cAMP signals by these PDEs at the plasma membrane [30]. However, whether these modifications affect $\beta$-AR regulation of cAMP levels in the cytosol and the local regulation of $I_{\mathrm{Ca}, \mathrm{L}}$ was not investigated. Thus, this study was designed to characterize the 
dynamic regulation of cytosolic cAMP and macroscopic $I_{\mathrm{Ca}, \mathrm{L}}$ by PDE3 and PDE4 in left ventricular myocytes (LVMs) from sham-operated (SHAM) and hypertrophied $(\mathrm{CH})$ rats, using a FRETbased cAMP sensor and the whole cell configuration of the patch-clamp technique. We show that balance between PDE3 and PDE4 in regulating the $\beta$-AR stimulation of cytosolic cAMP and $I_{\mathrm{Ca}, \mathrm{L}}$ is shifted from PDE4 in healthy cardiomyocytes to PDE3 in hypertrophied cells. 


\section{Methods}

All experiments were carried out according to the European Community guiding principles in the care and use of animals (2010/63/UE, 22 September 2010), the local Ethics committee (CEEA26 CAPSud) guidelines and the French decree $n^{\circ} 2013-118$, 1st February 2013 on the protection of animals used for scientific purposes (JORF $\mathrm{n}^{\circ} 0032,7$ February 2013 p2199, text $\left.\mathrm{n}^{\circ} 24\right)$. Animal experiments were approved by the French Ministry of Agriculture (prefectural agreement N²016108 and agreement to our animal facility $\mathrm{N}^{\circ} \mathrm{C}$ 92-019-01).

\subsection{Induction of cardiac hypertrophy $(\mathrm{CH})$ in Rats}

Fourty male Wistar rats were used in this study. $\mathrm{CH}$ was induced at three weeks of age (body weight $<60 \mathrm{~g}$ ). The animals were anesthetized (pentobarbital $60 \mathrm{mg} / \mathrm{kg}$ ) and a stainless steel hemoclip of $0.6 \mathrm{~mm}$ ID was placed on the ascending aorta via thoracic incision. Age-matched control rats (SHAM) underwent the same procedure without placement of the clip. Five weeks after surgery, rats were sacrificed and body, heart, lung, liver and kidney were weighted. Tibia length was measured using a vernier caliper (Table 1). Rats that exhibited signs of congestive HF (i.e. ascite, serous cavity effusion, or necrotic lungs, kidney or liver) were excluded from the study.

\subsection{Cardiomyocyte isolation, culture and infection}

Hearts were mounted on a Langendorff apparatus for retrograde perfusion of the aorta and coronaries with collagenase A (Roche, Meylan, France) as described previously [30]. Digestion time was 50 min for hearts from SHAM animals and varied between 90 and 120 min in the aortic stenosis group. At the end of the enzymatic digestion, the left ventricles were excised, chopped finely, and agitated manually to dissociate individual myocytes. Freshly isolated cells were 
suspended in minimal essential medium (MEM: M 4780; Sigma, St Louis, MO USA) containing $1.2 \mathrm{mM} \mathrm{Ca}{ }^{2+}, 2.5 \%$ fetal bovine serum (FBS, Invitrogen, Cergy-Pontoise, France), $1 \%$ penicillinstreptomycin and 2\% HEPES (pH 7.6) and plated on $35 \mathrm{~mm}$, laminin-coated culture dishes (10 $\mu \mathrm{g} / \mathrm{mL}$ laminin, $2 \mathrm{~h}$ ) at a density of $10^{4}$ cells per dish. After $1 \mathrm{~h}$ the medium was replaced by 300 $\mu \mathrm{L}$ of FBS-free MEM. A portion of the freshly isolated cells was incubated with an adenovirus encoding the cAMP sensor Epac2-camps [4] (MOI=1000 pfu/cell) for measurement of cytosolic cAMP as described below. The remaining non-infected cells were used for $I_{\mathrm{Ca}, \mathrm{L}}$ measurements. $I_{\mathrm{Ca}, \mathrm{L}}$ and $\mathrm{cAMP}$ measurements were performed at room temperature $2 \mathrm{~h}$ and $48 \mathrm{~h}$ after cell plating, respectively.

\subsection{Electrophysiological experiments}

Cell membrane capacitance and $I_{\mathrm{Ca}, \mathrm{L}}$ were measured using the patch-clamp technique in the wholecell configuration as described previously [5]. Voltage-clamp protocols were generated by a challenger/09-VM programmable function generator (Kinetic Software, Atlanta, GA, USA). The cells were voltage-clamped using a patch-clamp amplifier (model RK-400; Bio-Logic, Claix, France). Currents were analogue-filtered at $3 \mathrm{KHz}$ and digitally sampled at $10 \mathrm{KHz}$ using a 12-bit analogue-to-digital converter (DT2827; Data translation, Marlboro, MA, USA) connected to a compatible PC (386/33 Systempro; Compaq Computer Corp., Houston, TX, USA). Cell membrane capacitance was determined as the current elicited by a voltage ramp at $1 \mathrm{~V} / \mathrm{s}$ between $-90 \mathrm{mV}$ and $-70 \mathrm{mV}$. For $I_{\mathrm{Ca}, \mathrm{L}}$ measurement, the freshly isolated cells were depolarized every $8 \mathrm{~s}$ to $0 \mathrm{mV}$ during $400 \mathrm{~ms}$. Fast sodium current was inactivated by maintaining the cells at a holding potential of $-50 \mathrm{mV}$ and potassium currents were blocked by replacing all $\mathrm{K}^{+}$ions with external and internal $\mathrm{Cs}^{+}$. Extracellular solution contained (in mM): $\mathrm{NaCl} 107.1, \mathrm{CsCl} 20, \mathrm{NaHCO}_{3} 4, \mathrm{NaH}_{2} \mathrm{PO}_{4}$ 0.8, D- 
Glucose 5, sodium pyruvate 5, HEPES $10, \mathrm{CaCl}_{2} 1.8, \mathrm{MgCl}_{2} 1.8$ and was adjusted to $\mathrm{pH} 7.4$ with $\mathrm{NaOH}$. Control and drug-containing solutions were applied to the exterior of the cell by placing the cell at the opening of $250 \mu \mathrm{m}$ inner diameter capillary tubing. Patch electrodes $(0.5-1 \mathrm{M} \Omega)$ were filled with control internal solution containing (in mM): $\mathrm{CsCl} 118$, EGTA 5, $\mathrm{MgCl}_{2}$ 4, sodium phosphocreatine 5, Na2 ATP 3.1, $\mathrm{Na}_{2} \mathrm{GTP} 0.42, \mathrm{CaCl}_{2} 0.062$ (pCa 8.5), HEPES 10, adjusted to pH 7.3 with $\mathrm{CsOH}$. All the experiments were done at room temperature, and the temperature did not vary by more than $1^{\circ} \mathrm{C}$ in a given experiment.

\subsection{Live cell imaging}

Epac2-camps was used to measure cytosolic cAMP signals in SHAM and CH cardiomyocytes, as previously described [5]. Cells were maintained in a $\mathrm{K}^{+}$-Ringer solution containing (in $\mathrm{mM}$ ): $\mathrm{NaCl}$ 121.6, $\mathrm{KCl}$ 5.4, $\mathrm{MgCl}_{2}$ 1.8; $\mathrm{CaCl}_{2}$ 1.8; $\mathrm{NaHCO}_{3}$ 4, $\mathrm{NaH}_{2} \mathrm{PO}_{4}$ 0.8, D-glucose 5, sodium pyruvate 5, HEPES 10, adjusted to $\mathrm{pH}$ 7.4. Images were captured every $5 \mathrm{~s}$ using the 40x oil immersion objective of a Nikon TE 300 inverted epifluorescence microscope connected to a softwarecontrolled (Metafluor, Molecular Devices, Sunnyvale, CA, USA) cooled charge coupled (CCD) camera (Sensicam PE; PCO, Kelheim, Germany). Pixel size was $6.45 \mu \mathrm{m}$ and a binning of 2 was used thus image resolution was $(6.45 \times 2) / 40 \sim 0.32 \mu \mathrm{m}$. CFP was excited during $150-300 \mathrm{~ms}$ by a Xenon lamp (100 W, Nikon, Champigny-sur-Marne, France) using a 440/20BP filter and a 455LP dichroic mirror. Dual emission imaging of CFP and YFP was performed using an Optosplit II emission splitter (Cairn Research, Faversham, UK) equipped with a 495LP dichroic mirror and BP filters 470/30 and 535/30, respectively.

\subsection{Data analysis}


Cellular hypertrophy was evaluated by measuring cell membrane capacitance (Table 1). The maximal amplitude of $I_{\mathrm{Ca}, \mathrm{L}}$ was measured as the difference between the peak inward current and the current at the end of the 400-ms duration pulse at $0 \mathrm{mV}$. Currents were not compensated for capacitance and leak currents. Basal $I_{\mathrm{Ca}, \mathrm{L}}$ density $\left(\mathrm{d} I_{\mathrm{Ca}, \mathrm{L}}\right)$ was calculated for each experiment as the ratio of current amplitude to cell capacitance. In imaging experiments, average fluorescence intensity was measured in a region of interest comprising the entire cell or a significant part of the cell. Background was subtracted and YFP intensity was corrected for CFP spillover into the 535 $\mathrm{nm}$ channel before calculating the CFP/YFP ratio. Ratio images were obtained with ImageJ software (National Institutes of Health). Kinetic parameters ( $t_{1 / 2 \text { on }}$ and $t_{1 / 2 \text { off }}$ ) were determined using Microsoft Excel software. The time of the last baseline point before the signal first increased was defined as $t_{0}$. $t_{\text {peak }}$ represents the time required to reach the maximum of the signal from $t_{0}$. $t_{1 / 2 \text { on }}$ value is calculated as the time required for half maximal increase from $t_{0}$ while $t_{1 / 2 \text { off }}$ is calculated as the time required for half maximal decay from $t_{\text {peak. }}$. Data are expressed as mean \pm S.E.M. Statistical analysis was performed with GraphPad Prism software. Normal distribution was tested by the Shapiro-Wilk normality test. For simple two-group comparison, we used an unpaired Student t-test or a Mann-Whitney test when the data did not follow a normal distribution. Two-way, mixed-effects ANOVA with Sidak's post-hoc test was used to compare the time courses of cAMP and $I_{\mathrm{Ca}, \mathrm{L}}$ in SHAM and CH myocytes. Two-way ANOVA followed by Tukey's or Sidak's post-hoc test was used to compare maximal amplitude and kinetic parameters of cAMP and $I_{\mathrm{Ca}, \mathrm{L}}$ in SHAM and $\mathrm{CH}$ myocytes. Statistical difference was considered significant when $P<0.05$.

\subsection{Drugs}


Isoprenaline (Iso) was from Sigma (Saint Louis, MO USA). Cilostamide was from Tocris Bioscience (Ellisville, MI USA): It blocks PDE3 with an $\mathrm{IC}_{50}$ of about $0.042 \mu \mathrm{M}$ [31] and was used here at a $1 \mu \mathrm{M}$ concentration. Ro 20-1724 was kindly provided by Hoffman-La-Roche (Basel, Switzerland): It blocks PDE4 with an $\mathrm{IC}_{50}$ value around $1 \mu \mathrm{M}[32,33]$ and was used here at $10 \mu \mathrm{M}$. At these concentrations, Cil and Ro were shown to be selective for PDE3 and PDE4 respectively (Supplemental Table 1). 


\section{Results}

\subsection{Induction and characterization of cardiac hypertrophy in rats}

In order to study the $\beta$-AR regulation of cytosolic cAMP and $I_{\mathrm{Ca}, \mathrm{L}}$ during $\mathrm{CH}$, we used a model of pressure overload which we characterized in a previous study [30]. $\mathrm{CH}$ was generated by banding of the ascending aorta in male Wistar rats over a time period of 5 weeks as described in Methods. Anatomical data summarized in Table 1 indicate that heart weight (HW) of $\mathrm{CH}$ rats was increased by $46 \%$ compared to sham-operated (SHAM) rats, whereas body weight (BW) and tibia length (TL) were similar in both groups. The weight of lung, liver, kidney, and right ventricle were also unchanged (data not shown) indicating the absence of congestive HF. From these data, we can classify this model as compensated $\mathrm{CH}$ (Table 1).

\subsection{Regulation of cytosolic cAMP by transient $\beta$-AR stimulation in SHAM and CH cardiomyocytes}

To determine whether $\mathrm{CH}$ impacts on the dynamics of cytosolic cAMP, LVMs from SHAM and $\mathrm{CH}$ rats were transduced with an adenovirus encoding the FRET-based sensor, Epac2-camps [4]. This sensor can detect rapid changes in cAMP and is distributed throughout the cytosol [5]. Figure 1A shows pseudo color images of the CFP/YFP ratio in a SHAM and a $\mathrm{CH}$ myocyte before Iso stimulation (baseline), at the maximum of the Iso pulse $(100 \mathrm{nM}, 15 \mathrm{~s})$ and after washout of the $\beta$ AR agonist (recovery). In these examples, the CFP/YFP ratio was homogeneous in the cytosol, although in certain SHAM and CH myocytes a striated pattern was observed. However, no obvious difference in cAMP distribution within the cell was observed between SHAM and CH myocytes. The average time course of several experiments measuring cytosolic cAMP in response to a $15 \mathrm{~s}$ 
pulse of Iso is presented in Figure 1B. In both SHAM and $\mathrm{CH}$ myocytes, Iso induced a rapid and transient increase in the CFP/YFP ratio presenting similar maximal amplitude (Figure 1C), equivalent rising phase kinetics $\left(\mathrm{t}_{1 / 2 \mathrm{on}}\right.$, Figure $\left.1 \mathrm{D}\right)$ and comparable decay kinetics ( $\mathrm{t}_{1 / 2 \mathrm{off}}$, Figure $1 \mathrm{E})$.

\subsection{Modulation of $\beta$-AR cAMP signals by PDEs in SHAM and CH cardiomyocytes}

In healthy cardiomyocytes, cAMP generated by $\beta$-ARs is tightly controlled by PDE3 and PDE4 $[5,34]$. We tested whether this was also the case in $\mathrm{CH}$ myocytes. In the absence of Iso, selective inhibition of PDE3 with cilostamide (Cil, $1 \mu \mathrm{M})$ or PDE4 with Ro 20-1724 (Ro, $10 \mu \mathrm{M})$ had no effect on the FRET ratio in either SHAM or CH cells (data not shown). Since PDE4 plays a prominent role in the termination of $\beta$-AR cAMP signals in healthy rat cardiomyocytes [5] we first compared the effect of Ro on the cytosolic cAMP transient elicited by a 15 s pulse of Iso (100 nM) in SHAM and $\mathrm{CH}$ myocytes. As shown by the average time courses of Figure 2, Ro strongly increased the maximal amplitude and prolonged the duration of the cAMP response in both SHAM (Figure 2A) and $\mathrm{CH}$ myocytes (Figure 2B). The effects of Ro on the maximal amplitude (Figure 2C) and on the duration of the rising phase (Figure 2D) were not different between SHAM and $\mathrm{CH}$. In contrast, as shown in Figure 2E, the effect of Ro on the decay kinetics of the cAMP transient was significantly more pronounced in SHAM than in $\mathrm{CH}$ (in the presence of Ro, $\mathrm{t}_{1 / 2 \text { off }}$ was 273.3 $\pm 25.4 \mathrm{~s}$ in SHAM versus $176.3 \pm 15.9 \mathrm{~s}$ in $\mathrm{CH}, P<0.001)$. These results indicate that PDE4 plays a more prominent role to degrade cytosolic cAMP generated by $\beta$-AR in SHAM than in $\mathrm{CH}$ myocytes. 
In a next series of experiments, we compared the effect of PDE3 inhibition on the cytosolic cAMP transient in SHAM and CH myocytes (Figure 3). As shown in Figure 3A and Figure 3B, Cil (1 $\mu \mathrm{M})$ had a minimal effect in SHAM myocytes, whereas it potentiated the cAMP response to a pulse stimulation with Iso $(100 \mathrm{nM})$ in $\mathrm{CH}$ myocytes. Cil increased the amplitude of the response by $\sim 35 \%$ (from $+8.2 \pm 0.9 \%, \mathrm{n}=16$ to $+11.0 \pm 0.5 \%, \mathrm{n}=19, P<0.05$ ) in $\mathrm{CH}$ whereas it had no effect in SHAM (Figure 3C). In both groups, PDE3 inhibition did not modify the onset kinetics of the cAMP response (Figure 3D). Cil also induced a significant prolongation of the cAMP response to Iso in CH LVMs ( $\mathrm{t}_{1 / 2 \text { off }}$ was $52.6 \pm 3.5 \mathrm{~s}$ with Iso alone and $79.1 \pm 6.2 \mathrm{~s}$ in the presence of Cil) in contrast to SHAM LVMs (Figure 3E) These results indicate that while PDE3 plays a minor role in the regulation of $\beta$-AR cAMP signals in SHAM myocytes, its contribution becomes more important in $\mathrm{CH}$ myocytes. Taken together, these results suggest that in SHAM myocytes, PDE4 is major to control the amplitude and the duration of cytosolic cAMP signals elicited by a short $\beta$ AR stimulation whereas in $\mathrm{CH}$ myocytes, both PDE3 and PDE4 contribute to modulate the amplitude and the decay phase of the cAMP transient generated by a brief $\beta$-AR stimulation.

\subsection{Regulation of $I_{\mathrm{Ca}, \mathrm{L}}$ by transient $\beta$-AR stimulation in SHAM and $\mathrm{CH}$ cardiomyocytes}

In order to determine whether the regulation of $I_{\mathrm{Ca}, \mathrm{L}}$ by a brief $\beta$-AR stimulation is altered in $\mathrm{CH}$, the whole-cell configuration of the patch clamp technique was used. Consistent with cardiomyocyte hypertrophy, cell membrane capacitance, which is proportional to the surface of the plasma membrane, was significantly increased by $\sim 31 \%$ in $\mathrm{CH}$ versus SHAM LVMs. $I_{\mathrm{Ca}, \mathrm{L}}$ amplitude was also significantly larger $(+38 \%)$ in $\mathrm{CH}$ compared to SHAM LVMs, so that basal $I_{\mathrm{Ca}, \mathrm{L}}$ density, which is the ratio of $I_{\mathrm{Ca}, \mathrm{L}}$ current to membrane capacitance, was unchanged between the two groups (Table 1). As illustrated by the individual $I_{\mathrm{Ca}, \mathrm{L}}$ current traces of Figure $4 \mathrm{~A}$ and by 
the average time course of $I_{\mathrm{Ca}, \mathrm{L}}$ amplitude in Figure 4B, a brief application of Iso (100 nM, $\left.15 \mathrm{~s}\right)$ elicited an apparently similar transient increase in $I_{\mathrm{Ca}, \mathrm{L}}$ in both groups. Indeed, both the maximal increase in $I_{\mathrm{Ca}, \mathrm{L}}$ and recovery rate were unchanged (Figure $4 \mathrm{C}$ and $4 \mathrm{E}$ ). However, the kinetics of $I_{\mathrm{Ca}, \mathrm{L}}$ augmentation were significantly slower in $\mathrm{CH}$ compared to SHAM LVMs $\left(\mathrm{t}_{1 / 2 \mathrm{on}}=30.1 \pm 1.8 \mathrm{~s}\right.$, $\mathrm{n}=17$ in $\mathrm{CH}$ versus $21.9 \pm 0.9 \mathrm{~s}, \mathrm{n}=27$ in SHAM, $P<0.001$, Figure 4D).

\subsection{Regulation of $I_{\mathrm{Ca}, \mathrm{L}}$ by PDEs in SHAM and CH cardiomyocytes}

In order to determine whether PDE regulation of $I_{\mathrm{Ca}, \mathrm{L}}$ is modified in $\mathrm{CH}$, we first applied Cil (1 $\mu \mathrm{M})$ or Ro $(10 \mu \mathrm{M})$ in the absence of $\beta$-AR stimulation in SHAM and CH cells. However, neither

inhibitor alone had an effect on basal $I_{\mathrm{Ca}, \mathrm{L}}$ (Supplemental Figure 1). We next tested the effect of PDE4 inhibition with Ro on top of a transient $\beta$-AR stimulation with Iso (100 nM, $15 \mathrm{~s})$. As shown in Figure $5 \mathrm{~A}$ and $5 \mathrm{~B}$, in both $\mathrm{SHAM}$ and $\mathrm{CH}$ LVMs, Ro potentiated the Iso-stimulated $I_{\mathrm{Ca}, \mathrm{L}}$ In SHAM, PDE4 inhibition increased the maximal $I_{\mathrm{Ca}, \mathrm{L}}$ amplitude by $~ 50 \%$ (Figure $5 \mathrm{C}$ ), had no effect on the rising kinetics (Figure 5D) and nearly doubled $I_{\mathrm{Ca}, \mathrm{L}}$ recovery (Figure $5 \mathrm{E}, \mathrm{t}_{1 / 2 \text { off }}$ was $128.4 \pm$ $11.7 \mathrm{~s}, \mathrm{n}=16$ with Iso alone and $219.1 \pm 24.8 \mathrm{~s}, \mathrm{n}=9$ in the presence of Ro, $P<0.01$ ). However in $\mathrm{CH}$ myocytes, Ro did not significantly increase the maximum of $I_{\mathrm{Ca}, \mathrm{L}}$ response to Iso (Figure $5 \mathrm{C}$ ) and appeared less effective in prolonging its decay phase (Figure $5 \mathrm{E}, \mathrm{t}_{1 / 2 \text { off }}$ was $166.0 \pm 23.2 \mathrm{~s}$, $\mathrm{n}=10$ with Iso alone and $249.3 \pm 24.8 \mathrm{~s}, \mathrm{n}=9$ in the presence of Ro, $P<0.05)$. These data suggest an altered regulation of $I_{\mathrm{Ca}, \mathrm{L}}$ by PDE4 in $\mathrm{CH}$ myocytes.

In a second series of experiments, the effect of Cil $(1 \mu \mathrm{M})$ was tested on the $\beta$-AR regulation of $I_{\mathrm{Ca}, \mathrm{L}}$ (Figure 6). In SHAM LVMs, Cil showed a strong tendency to potentiate the maximal increase of $I_{\mathrm{Ca}, \mathrm{L}}$ in response to Iso pulse stimulation (Figure $6 \mathrm{~A}$ and $6 \mathrm{C}$ ) whereas there was no potentiating effect of Cil on $I_{\mathrm{Ca}, \mathrm{L}}$ maximal amplitude in $\mathrm{CH}$ LVMs (Figure 6B and 6C). PDE3 inhibition did 
not modify the rising kinetics of $I_{\mathrm{Ca}, \mathrm{L}}$ in either group (Figure $6 \mathrm{D}$ ), whereas it slowed down $I_{\mathrm{Ca}, \mathrm{L}}$

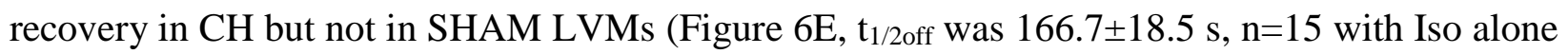
and 238.1 $\pm 27.2 \mathrm{~s}, \mathrm{n}=17$ in the presence of Cil, $P<0.05)$. These results highlight two main differences in the regulation of $I_{\mathrm{ca}, \mathrm{L}}$ by PDE3/4 between SHAM and CH cells: First, whereas both PDE3 and PDE4 appear to limit the maximal $I_{\mathrm{Ca}, \mathrm{L}}$ amplitude upon a transient $\beta$-AR stimulation in SHAM myocytes, this effect is lost in $\mathrm{CH}$ myocytes. Second, whereas PDE4 is predominant to control the termination of Iso-stimulated $I_{\mathrm{Ca}, \mathrm{L}}$ and is able to mask the contribution of PDE3 in SHAM myocytes as shown in a previous study[5], it was no longer the case in $\mathrm{CH}$ myocytes.

\subsection{Selective alterations in cytosolic cAMP and $I_{\mathrm{Ca}, \mathrm{L}}$ compartments in cardiac hypertrophy}

In Figure 7 , the kinetics of cytosolic cAMP and $I_{\mathrm{Ca}, \mathrm{L}}$ transients induced by Iso alone or in the presence of PDE inhibitors are summarized and compared between SHAM and CH myocytes. Additionally, kinetics of CFP/YFP ratio are compared to those of $I_{\mathrm{Ca}, \mathrm{L}}$ within the same group. This latter comparison highlights the faster onset and decay kinetics of cAMP compared to $I_{\mathrm{Ca}, \mathrm{L}}$, in SHAM and $\mathrm{CH}$ myocytes, as observed previously in normal rat cardiomyocytes [5], which indicates that molecular events occurring downstream of cAMP, i.e. phosphorylation and dephosphorylation of LTCC or a closely associated protein, are rate-limiting for both the rise and the decay of $I_{\mathrm{Ca}, \mathrm{L}}$. When both PDEs are functional, the only difference between SHAM and CH cells is a slower rising phase of $I_{\mathrm{Ca}, \mathrm{L}}$ in $\mathrm{CH}$ cells (Figures 7A and 7B). This difference is no longer observed when either PDE3 or PDE4 are blocked (Figures 7C and 7E). Blockade of PDE4 slows the decay phase of cAMP and $I_{\mathrm{Ca}, \mathrm{L}}$ transients compared to Iso in both groups, underlining the major role played by PDE4 in controlling the duration of cAMP-triggered events. In the presence of Ro, the FRET signal returns more rapidly to baseline in $\mathrm{CH}$ than in SHAM myocytes, in contrast to 
the decrease rates of $I_{\mathrm{Ca}, \mathrm{L}}$ which remain similar between SHAM and $\mathrm{CH}$ cells (Figure 7D). These results suggest that in $\mathrm{CH}$ compared to SHAM, there is more PDE activity remaining in the cytosol (probably PDE3), whereas it is unchanged nearby L-type $\mathrm{Ca}^{2+}$ channels. In contrast, when PDE3 is blocked the duration of the decay phase of the cAMP transient is similar in both groups, whereas $I_{\mathrm{Ca}, \mathrm{L}}$ decay becomes significantly slower in $\mathrm{CH}$ cells compared to SHAM (Figure 7F), which is consistent with altered regulation of $I_{\mathrm{Ca}, \mathrm{L}}$ by PDE4 in $\mathrm{CH}$ cells. 


\section{Discussion}

The major goal of this study was to determine how $\mathrm{CH}$ induced by pressure overload modifies the dynamic regulation of cytosolic cAMP and $I_{\mathrm{Ca}, \mathrm{L}}$ by PDE3 and PDE4 upon a brief $\beta$-AR stimulation, which mimics the sympathetic nerve discharge elicited during a startle response. While the amplitude and the duration of the cytosolic cAMP and $I_{\mathrm{Ca}, \mathrm{L}}$ responses were preserved in $\mathrm{CH}$, our results reveal a specific rearrangement of PDE3 and PDE4 in the bulk cytosol and in the vicinity of LTCCs that maintains the homeostasis of the $\beta$-AR response in diseased myocytes (Figure 8). Indeed, whereas PDE4 was the main family modulating cytosolic $\beta$-AR cAMP transients in SHAM, both PDE3 and PDE4 controlled the amplitude and the recovery of these cAMP signals in $\mathrm{CH}$. The subcellular reorganization of PDEs in CH LVMs also modified the $\beta$-AR regulation of $I_{\mathrm{ca}, \mathrm{L}}$ by inducing i) a slower rate of $I_{\mathrm{Ca}, \mathrm{L}}$ increase upon Iso stimulation; ii) an abrogated modulation by PDE3 and PDE4 of Iso-augmented maximal $I_{\mathrm{Ca}, \mathrm{L}}$ amplitude; and iii) a rearrangement in the PDEs governing the recovery of $I_{\mathrm{Ca}, \mathrm{L}}$ from $\beta$-AR stimulation. This molecular remodeling likely prevents abnormal prolongation of $\mathrm{Ca}^{2+}$ influx after $\beta$-AR stimulation and consequent deleterious $\mathrm{Ca}^{2+}$ overload in $\mathrm{CH}$.

The conclusions drawn in the present paper rely on the comparison of cardiomyocytes isolated from sham-operated rats or rats with aortic banding. As indicated in the Methods section, the digestion time had to be increased to isolate $\mathrm{CH}$ myocytes, most likely due to the increased cardiac mass and fibrosis in banded animals [35]. Although this was not associated with readily observable damages of $\mathrm{CH}$ myocytes, this constitutes a limitation since we cannot exclude that it contributed to some of the differences observed between normal and $\mathrm{CH}$ myocytes. In addition, all experiments of this study were performed at room temperature. Although experimental conditions of cAMP and $I_{\mathrm{Ca}, \mathrm{L}}$ measurements were rigorously similar between normal and $\mathrm{CH}$ myocytes, we cannot 
exclude a potential impact of temperature on some of the results reported here. In this study, cAMP was measured with an untargeted FRET sensor in the bulk cytosol. As indicated in the result section, the CFP/YFP ratio was homogeneous in most cells, but a striated pattern was observed in some cells. Based on our previous observations of similar striations upon injection of the FRETbased cAMP sensor FlCRhR, or upon injection of a $70 \mathrm{kDa}$ fluorescein-dextran molecule into frog cardiomyocytes [36], we think that these striations reflect accumulation of the probe in less crowded regions of the myocyte. In the case of the genetically-encoded Epac2-camps used in the present study, this phenomenon is probably influenced by the expression level. For a given multiplicity of infection, there is a cell-to-cell variability in the amount of sensor which is expressed in different myocytes, which probably explains the occurrence of striations in some cells and not in others. Importantly however, these striations could be observed both in sham and hypertrophied myocytes so that the two cell populations did not differ in this respect. While the modulation of $\beta$-ARs cAMP signals by PDE3 and PDE4 in the bulk cytosol have been largely documented in normal cardiomyocytes, much less is known in heart disease [27]. However, due to the compartmentalized nature of cAMP, it should be kept in mind that the changes reported in this study concern global cAMP levels and may not apply to specific microdomains in cardiomyocytes.

In $\mathrm{CH}$ myocytes, the cytosolic cAMP transient generated by a brief $\beta$-AR stimulation was not different from that observed in SHAM myocytes. Given that $\beta$-AR desensitization is a hallmark of HF [11] and is also observed in $\mathrm{CH}$ induced by aortic banding [37], one could have expected the cytosolic cAMP transient to be reduced. However, along with $\beta$-AR desensitization, the total cAMP-hydrolytic activity is decreased in this model of $\mathrm{CH}$ [30]. Therefore, these results suggest that during $\mathrm{CH}$, a reduction in cytosolic cAMP-PDE activity compensates for $\beta$-AR 
desensitization, resulting in unchanged cAMP transient in this compartment. At variance with this result, a decreased cAMP response to sustained $\beta$-AR stimulation was observed in $\mathrm{CH}$ myocytes when cAMP was measured with CNG channels at the sarcolemma [30]. This suggests that compartment-specific cAMP alterations occur during $\mathrm{CH}$, where local rather than global PDE activity determines the response [38]. Alternatively, a difference linked to the stimulation protocol (i.e. pulse stimulation used in the present study versus cumulative Iso application in the previous one) cannot be excluded. Indeed, during cumulative concentration response experiments, prolonged agonist application should favour $\beta$-AR desensitization compared to a $15 \mathrm{~s}$ pulse stimulation.

The next question was whether the control of $\beta$-AR cAMP signals by PDE3 and PDE4 differ in SHAM versus $\mathrm{CH}$ myocytes. Our results confirm previous studies showing that PDE4 is the main PDE degrading cytosolic cAMP in healthy adult cardiomyocytes from rats and mice [5, 34]. Besides, PDE4 is able to compensate for PDE3 inhibition in the cytosol of normal cells, a property which is likely facilitated by PKA-dependent activation of PDE4 [5]. In contrast, in $\mathrm{CH}$ cells both PDE3 and PDE4 limit the amplitude and duration of the cAMP transient. The decreased contribution of PDE4 in the bulk cytosol of $\mathrm{CH}$ cells is consistent with the decreased PDE4 activity observed in this model [30] and with a previous study in cardiomyocytes from mice with transaortic constriction (TAC) [27]. Interestingly, when PDE4 was inhibited, cAMP decay was faster in $\mathrm{CH}$ compared to SHAM, implying that the remaining cytosolic cAMP-PDE activity is higher in $\mathrm{CH}$ than in SHAM (Figure 7D). Importantly, this difference was not observed when PDE3 was inhibited (Figure 7F). These observations, together with the fact that PDE3 is largely predominant to terminate $\beta$-AR cAMP responses when PDE4 is inhibited [5], strongly suggest that the relative contribution of PDE3 to cAMP degradation in the cytosol is increased in $\mathrm{CH}$ myocytes. This 
interpretation may seem at odds with the decreased total PDE3 activity in this model [30]. However, because PDE4 decreases even more than PDE3, the PDE3/PDE4 activity ratio is actually increased in CH compared to SHAM [30]. In addition, it is likely that the global PDE3 activity measured in vitro, at a fixed substrate concentration, differs from the PDE3 activity in intact cardiomyocytes challenged with Iso and Ro 20-1724. In particular, PDE3 regulation by cGMP is not taken into account in such enzymatic assay. cGMP effectively inhibits the cAMP-hydrolytic activity of PDE3 with $K_{i}$ value of about $0.06-0.6 \mu \mathrm{M}$ [2] and its concentration is decreased in pathological cardiac hypertrophy [39]. Thus, decreased cGMP levels in $\mathrm{CH}$ cells could be involved in PDE3 activation, as occurs in aortic rings with endothelial dysfunction due to heart failure in rats [40]. In addition, recent studies have documented a decreased localization of PDE3 in specific microdomains of the plasma membrane in $\mathrm{CH}$ [28] and HF [29] which could result in the relocalization of PDE3 in the cytosol. Alternatively, we cannot exclude that other PDEs participate in this difference. Possible candidates include PDE1 and PDE2 which are increased in animal models and human HF, albeit not in $\mathrm{CH}$ [41-43] and PDE8, which was reported in mouse cardiomyocytes [44]. Although we did not test directly the potential contribution of these PDEs to cAMP-degradation in $\mathrm{CH}$ cardiomyocytes, it should be emphasized that they represent minor contributors to cAMP hydrolysis compared to PDE3 and PDE4, not only in SHAM but also in CH ventricular myocytes [30].

$I_{\mathrm{Ca}, \mathrm{L}}$ is a critical determinant of $\mathrm{Ca}^{2+}$-induced $\mathrm{Ca}^{2+}$ release which constitutes a canonical example of local regulation by $\beta$-ARs and PDEs $[5,45,46]$. Thus, using the same protocol of brief $\beta$-AR stimulation as for cytosolic cAMP, we compared the dynamic stimulation of $I_{\mathrm{Ca}, \mathrm{L}}$ in SHAM and $\mathrm{CH}$, and the influence of PDE3 and PDE4 in this process. In the absence of $\beta$-AR stimulation, basal $I_{\mathrm{Ca}, \mathrm{L}}$ density was similar between SHAM and $\mathrm{CH}$ myocytes, which is consistent with a 
number of previous studies [47-49]. While most analyses point to a maintenance of whole-cell $I_{\mathrm{Ca}, \mathrm{L}}$ density in $\mathrm{CH}$ and $\mathrm{HF}$, an increased open probability has been evidenced at the single channel level $[50,51]$. A possible explanation is that diseased myocytes have fewer but more active channels [52-54].

Upon pulse $\beta$-AR stimulation, $I_{\mathrm{Ca}, \mathrm{L}}$ augmented more slowly in $\mathrm{CH}$ than in SHAM, although the onset kinetics of cAMP in the cytosol were not modified. These results are not necessarily contradictory if one considers that submembrane and cytosolic cAMP signals display different kinetics and represent distinct microdomains separated by restricted diffusion [5]. In addition, mechanisms downstream of cAMP may explain this difference. Indeed, pathological $\mathrm{CH}$ and $\mathrm{HF}$ are associated with altered PKA expression $[55,56]$, reorganized association with AKAPs [57, 58], and increased phosphatase activity [59, 60], all of which could contribute to a slower phosphorylation of $I_{\mathrm{Ca}, \mathrm{L}}$ in $\mathrm{CH}$ LVMs. Although upon $\beta$-AR stimulation $I_{\mathrm{Ca}, \mathrm{L}}$ increased slower in $\mathrm{CH}$ than in SHAM, the peak stimulation was similar. This contrasts with previous studies showing that the maximal response to Iso is depressed in $\mathrm{CH}$ and $\mathrm{HF}[47,54]$. As indicated previously for cAMP, this might be explained by the different protocols used in the different studies, i.e. sustained versus pulse stimulation. In SHAM, application of $100 \mathrm{nM}$ Iso during $15 \mathrm{~s}$ was not maximal since $I_{\mathrm{Ca}, \mathrm{L}}$ could be further potentiated by inhibition of PDE3 or PDE4. Interestingly, this was not the case in $\mathrm{CH}$. $I_{\mathrm{Ca}, \mathrm{L}}$ amplitude is a crucial determinant of systolic $\mathrm{Ca}^{2+}$ concentration and therefore contraction. Hence, these results are consistent with an attenuated contractile response to PDE3 and PDE4 inhibitors in rats with cardiac hypertrophy [61] and with the decreased inotropic effect of PDE3 inhibitors in failing human hearts [19] or in dogs with HF [14]. Mechanistically, the blunted effect of PDE inhibitors could be due to impaired regulation of subsarcolemmal cAMP by PDE3 and PDE4, as shown previously [30]. In the case of PDE3, this is corroborated by recent 
independent studies showing decreased contribution of this PDE to cAMP hydrolysis in specific microdomains of the plasma membrane.[28, 29] The blunted effect of PDE3/4 inhibitors on maximal $I_{\mathrm{Ca}, \mathrm{L}}$ amplitude could also be related to a larger fraction of LTCC being activated already in basal conditions in $\mathrm{CH}$ myocytes, as indicated by a number of previous reports in failing myocytes. [50-54, 62] Hence, similar to what was reported for PDE4 and RyR2 in HF [10], a decrease in PDE activity nearby $\mathrm{Ca}^{2+}$ channels might contribute to increased basal activity of LTCC and therefore to a lack of the potentiating effect of PDE inhibitors on maximal $I_{\mathrm{Ca}, \mathrm{L}}$ in $\mathrm{CH}$ myocytes.

We have shown previously in rat ventricular myocytes that $I_{\mathrm{Ca}, \mathrm{L}}$ decay following a transient Iso stimulation is not modified by PDE3 inhibition, as shown here in SHAM (Figure 4E). However, concomitant PDE3 and PDE4 inhibition considerably slowed $I_{\mathrm{Ca}, \mathrm{L}}$ recovery in a similar way as IBMX, indicating a critical role of these two PDE families for $I_{\mathrm{Ca}, \mathrm{L}}$ recovery in normal myocytes [5]. Although concomitant inhibition of PDE3 and PDE4 in SHAM and CH would have been useful to ensure that the situation is the same especially in hypertrophied myocytes, analysis of the recovery kinetics of $I_{\mathrm{Ca}, \mathrm{L}}$ following $\beta$-AR stimulation suggests that both PDE3 and PDE4 are required to terminate the response in $\mathrm{CH}$ and further support the notion that PDE4 regulation of $I_{\mathrm{Ca}, \mathrm{L}}$ is impaired in $\mathrm{CH}$. Indeed, when PDE3 was blocked, $I_{\mathrm{Ca}, \mathrm{L}}$ decay was significantly slower in $\mathrm{CH}$, whereas it was unchanged when PDE4 was inhibited (Figure 7F and 7D). These results strongly argue for altered regulation of $I_{\mathrm{Ca}, \mathrm{L}}$ by PDE4 during $\mathrm{CH}$. Among the various PDE4 isoforms expressed in cardiomyocytes, we showed that PDE4B is predominant for $\beta$-AR regulation of $I_{\mathrm{Ca}, \mathrm{L}}[6]$ and is decreased in $\mathrm{CH}$ [30]. In normal cardiomyocytes, PDE4B co-localizes with LTCCs in the T-tubules [6] and during HF, LTCCs are redistributed from T-tubules to the 
peripheral sarcolemma.[51, 62] Thus, decreased PDE4B expression and/or a rearrangement away from LTCCs could contribute to abnormal regulation of $I_{\mathrm{Ca}, \mathrm{L}}$ by PDE4 in $\mathrm{CH}$.

The complete loss of PDE4B in mice potentiates $\beta$-AR stimulation of $I_{\mathrm{Ca}, \mathrm{L}}$ and the occurrence of spontaneous $\mathrm{Ca}^{2+}$ release events, as well as the susceptibility to ventricular tachycardia [6]. In CH, our results indicate that the contribution of PDE3 to $I_{\mathrm{Ca}, \mathrm{L}}$ recovery after $\beta$-AR stimulation compensates for impaired PDE4 regulation, and may therefore constitute a safety mechanism that preserves hypertrophic cardiomyocytes from $\mathrm{Ca}^{2+}$ overload and arrhythmias. Although PDE3 is classically considered as the major PDE regulating cardiac contractility in large mammals [63], there is increasing evidence that PDE4 contributes to $\beta$-AR regulation of $\mathrm{cAMP}$ and $\mathrm{ECC}$ in $\operatorname{dog}$ [64], pig [23] and human [65]. Thus, hypothesizing that PDE4 regulation of $I_{\mathrm{Ca}, \mathrm{L}}$ is impaired in human HF, this could contribute to the increased risk of arrhythmias observed in this condition, especially in the context of chronic treatment with PDE3 inhibitors, which were shown to increase cardiac arrhythmias and mortality in severe HF [66-68].

\section{Funding}

This work was supported by a joint fellowship from the French and Lebanese governments, Partenariat Hubert Curien, CEDRE $\mathrm{N}^{\circ}$ 42338SA to A.A.G and G.V. UMR-S1180 is a member of the Laboratory of Excellence LERMIT supported by a grant from the French National Research Agency (ANR-10-LABX-33) under the program "Investissements d'Avenir" ANR-11-IDEX0003-01. This work was also funded by grant ANR R19163LL to GV, ANR-16-ECVD-0007-01 (PDE4HEART) to RF and the Fondation de France (to G.V.).

\section{Acknowledgments}


We thank Florence Lefebvre and Patrick Lechène for skillful technical assistance. We are also grateful to Dr. Viacheslav Nikolaev (University of Hamburg), Dr. Stefan Engelhardt (University of Munich) and Dr. Martin Lohse (University of Würzburg) for the adenovirus encoding Epac2camps.

\section{Disclosure}

None. 


\section{References}

[1] D.M. Bers, Calcium cycling and signaling in cardiac myocytes, Annu. Rev. Physiol. 70 (2008) 23-49.

[2] O.E. Osadchii, Myocardial phosphodiesterases and regulation of cardiac contractility in health and cardiac disease, Cardiovasc. Drugs Ther. 21(3) (2007) 171-94.

[3] M. Mongillo, T. McSorley, S. Evellin, A. Sood, V. Lissandron, A. Terrin, et al., Fluorescence resonance energy transfer-based analysis of cAMP dynamics in live neonatal rat cardiac myocytes reveals distinct functions of compartmentalized phosphodiesterases, Circ. Res. 95(1) (2004) 6775.

[4] V.O. Nikolaev, M. Bunemann, L. Hein, A. Hannawacker, M.J. Lohse, Novel single chain cAMP sensors for receptor-induced signal propagation, J. Biol. Chem. 279(36) (2004) 37215-8.

[5] J. Leroy, A. Abi-Gerges, V.O. Nikolaev, W. Richter, P. Lechene, J.L. Mazet, et al., Spatiotemporal dynamics of $\beta$-adrenergic cAMP signals and L-type $\mathrm{Ca}^{2+}$ channel regulation in adult rat ventricular myocytes: role of phosphodiesterases, Circ. Res. 102(9) (2008) 1091-100.

[6] J. Leroy, W. Richter, D. Mika, L.R. Castro, A. Abi-Gerges, M. Xie, et al., Phosphodiesterase $4 \mathrm{~B}$ in the cardiac L-type $\mathrm{Ca}^{2+}$ channel complex regulates $\mathrm{Ca}^{2+}$ current and protects against ventricular arrhythmias in mice, J. Clin. Invest. 121(7) (2011) 2651-61.

[7] S. Beca, F. Ahmad, W. Shen, J. Liu, S. Makary, N. Polidovitch, et al., PDE3A Regulates Basal Myocardial Contractility Through Interacting with SERCA2a-Signaling Complexes in Mouse Heart, Circ. Res. 112 (2013) 289-97.

[8] S. Beca, P.B. Helli, J.A. Simpson, D. Zhao, G.P. Farman, P.P. Jones, et al., Phosphodiesterase 4D regulates baseline sarcoplasmic reticulum $\mathrm{Ca}^{2+}$ release and cardiac contractility, independently of L-type $\mathrm{Ca}^{2+}$ current, Circ. Res. 109(9) (2011) 1024-30.

[9] F. Ahmad, W. Shen, F. Vandeput, N. Szabo-Fresnais, J. Krall, E. Degerman, et al., Regulation of sarcoplasmic reticulum $\mathrm{Ca}^{2+}$ ATPase 2 (SERCA2) activity by phosphodiesterase 3A (PDE3A) in human myocardium: phosphorylation-dependent interaction of PDE3A1 with SERCA2, J. Biol. Chem. 290(11) (2015) 6763-76.

[10] S.E. Lehnart, X.H. Wehrens, S. Reiken, S. Warrier, A.E. Belevych, R.D. Harvey, et al., Phosphodiesterase 4D deficiency in the ryanodine-receptor complex promotes heart failure and arrhythmias., Cell 123(1) (2005) 25-35.

[11] M.J. Lohse, S. Engelhardt, T. Eschenhagen, What is the role of $\beta$-adrenergic signaling in heart failure?, Circ. Res. 93(10) (2003) 896-906.

[12] V.O. Nikolaev, A. Moshkov, A.R. Lyon, M. Miragoli, P. Novak, H. Paur, et al., $\beta_{2}$-adrenergic receptor redistribution in heart failure changes cAMP compartmentation, Science 327(5973) (2010) 1653-7.

[13] C.J. Smith, R. Huang, D. Sun, S. Ricketts, C. Hoegler, J.Z. Ding, et al., Development of decompensated dilated cardiomyopathy is associated with decreased gene expression and activity of the milrinone-sensitive cAMP phosphodiesterase PDE3A, Circulation 96(9) (1997) 3116-23.

[14] N. Sato, K. Asai, S. Okumura, G. Takagi, R.P. Shannon, Y. Fujita-Yamaguchi, et al., Mechanisms of desensitization to a PDE inhibitor (milrinone) in conscious dogs with heart failure, Am. J. Physiol. 276(5 Pt 2) (1999) H1699-705.

[15] B. Ding, J. Abe, H. Wei, Q. Huang, R.A. Walsh, C.A. Molina, et al., Functional role of phosphodiesterase 3 in cardiomyocyte apoptosis: implication in heart failure, Circulation 111(19) (2005) 2469-76. 
[16] B. Ding, J. Abe, H. Wei, H. Xu, W. Che, T. Aizawa, et al., A positive feedback loop of phosphodiesterase 3 (PDE3) and inducible cAMP early repressor (ICER) leads to cardiomyocyte apoptosis, Proc. Natl. Acad. Sci. U. S. A. 102(41) (2005) 14771-6.

[17] W. Richter, M. Xie, C. Scheitrum, J. Krall, M.A. Movsesian, M. Conti, Conserved expression and functions of PDE4 in rodent and human heart, Basic Res. Cardiol. 106(2) (2011) 249-62.

[18] M.A. Movsesian, C.J. Smith, J. Krall, M.R. Bristow, V.C. Manganiello, Sarcoplasmic reticulum-associated cyclic adenosine 5'-monophosphate phosphodiesterase activity in normal and failing human hearts., J. Clin. Invest. 88(1) (1991) 15-9.

[19] H. von der Leyen, U. Mende, W. Meyer, J. Neumann, M. Nose, W. Schmitz, et al., Mechanism underlying the reduced positive inotropic effects of the phosphodiesterase III inhibitors pimobendan, adibendan and saterinone in failing as compared to nonfailing human cardiac muscle preparations, Naunyn Schmiedebergs Arch. Pharmacol. 344(1) (1991) 90-100.

[20] W.C. Chiu, J. Kedem, H.R. Weiss, J. Tse, B.V. Cheinberg, P.M. Scholz, Milrinone, a cyclic AMP-phosphodiesterase inhibitor, has differential effects on regional myocardial work and oxygen consumption in experimental left ventricular hypertrophy, Cardiovasc. Res. 28(9) (1994) $1360-5$.

[21] K. Takahashi, T. Osanai, T. Nakano, M. Wakui, K. Okumura, Enhanced activities and gene expression of phosphodiesterase types 3 and 4 in pressure-induced congestive heart failure, Heart Vessels 16(6) (2002) 249-56.

[22] W. Mokni, T. Keravis, N. Etienne-Selloum, A. Walter, M.O. Kane, V.B. Schini-Kerth, et al., Concerted regulation of cGMP and cAMP phosphodiesterases in early cardiac hypertrophy induced by angiotensin II, PLoS One 5(12) (2010) e14227.

[23] D. Mika, P. Bobin, M. Lindner, A. Boet, A. Hodzic, F. Lefebvre, et al., Synergic PDE3 and PDE4 control intracellular cAMP and cardiac excitation-contraction coupling in a porcine model, J. Mol. Cell. Cardiol. 133 (2019) 57-66.

[24] C.C. Sucharov, S.J. Nakano, D. Slavov, J.A. Schwisow, E. Rodriguez, K. Nunley, et al., A PDE3A Promoter Polymorphism Regulates cAMP-Induced Transcriptional Activity in Failing Human Myocardium, J. Am. Coll. Cardiol. 73(10) (2019) 1173-1184.

[25] A. Ghigo, A. Perino, H. Mehel, A.J. Zahradnikova, F. Morello, J. Leroy, et al., PI3Kgamma Protects against Catecholamine-Induced Ventricular Arrhythmia through PKA-mediated Regulation of Distinct Phosphodiesterases, Circulation 126 (2012) 2073-83.

[26] P. Bobin, A. Varin, F. Lefebvre, R. Fischmeister, G. Vandecasteele, J. Leroy, Calmodulin kinase II inhibition limits the pro-arrhythmic $\mathrm{Ca}^{2+}$ waves induced by cAMP-phosphodiesterase inhibitors, Cardiovasc. Res. 110(1) (2016) 151-61.

[27] J.U. Sprenger, R.K. Perera, J.H. Steinbrecher, S.E. Lehnart, L.S. Maier, G. Hasenfuss, et al., In vivo model with targeted cAMP biosensor reveals changes in receptor-microdomain communication in cardiac disease, Nat Commun 6 (2015) 6965.

[28] R.K. Perera, J. Sprenger, J.H. Steinbrecher, D. Hubscher, S.E. Lehnart, M. Abesser, et al., Microdomain Switch of cGMP-Regulated Phosphodiesterases Leads to ANP-Induced Augmentation of $\beta$-Adrenoceptor-Stimulated Contractility in Early Cardiac Hypertrophy, Circ. Res. 116 (2015) 1304-1311.

[29] Z. Bastug-Ozel, P.T. Wright, A.E. Kraft, D. Pavlovic, J. Howie, A. Froese, et al., Heart failure leads to altered $\beta_{2}$-adrenoceptor/cyclic adenosine monophosphate dynamics in the sarcolemmal phospholemman/Na,K ATPase microdomain, Cardiovasc. Res. 115(3) (2019) 546-555. 
[30] A. Abi-Gerges, W. Richter, F. Lefebvre, P. Mateo, A. Varin, C. Heymes, et al., Decreased expression and activity of cAMP phosphodiesterases in cardiac hypertrophy and its impact on $\beta$ adrenergic cAMP signals, Circ. Res. 105(8) (2009) 784-92.

[31] J.-C. Stoclet, T. Keravis, N. Komas, C. Lugnier, Cyclic nucleotide phosphodiesterases as therapeutic targets in cardiovascular diseases., Exp Op Invest Drugs 4 (1995) 1081-1100.

[32] R.J. Rose, H. Liu, D. Palmer, D.H. Maurice, Cyclic AMP-mediated regulation of vascular smooth muscle cell cyclic AMP phosphodiesterase activity, Br. J. Pharmacol. 122(2) (1997) 23340.

[33] T.C. Rich, T.E. Tse, J.G. Rohan, J. Schaack, J.W. Karpen, In vivo assessment of local phosphodiesterase activity using tailored cyclic nucleotide-gated channels as cAMP sensors, J. Gen. Physiol. 118(1) (2001) 63-78.

[34] V.O. Nikolaev, M. Bunemann, E. Schmitteckert, M.J. Lohse, S. Engelhardt, Cyclic AMP imaging in adult cardiac myocytes reveals far-reaching $\beta_{1}$-adrenergic but locally confined $\beta_{2}$ adrenergic receptor-mediated signaling, Circ. Res. 99(10) (2006) 1084-91.

[35] E.E. Creemers, Y.M. Pinto, Molecular mechanisms that control interstitial fibrosis in the pressure-overloaded heart, Cardiovasc. Res. 89(2) (2011) 265-72.

[36] J.M. Goaillard, P.V. Vincent, R. Fischmeister, Simultaneous measurements of intracellular cAMP and L-type $\mathrm{Ca}^{2+}$ current in single frog ventricular myocytes, J. Physiol. 530(Pt 1) (2001) 79-91.

[37] B. Chevalier, P. Mansier, F. Callens-el Amrani, B. Swynghedauw, $\beta$-adrenergic system is modified in compensatory pressure cardiac overload in rats: physiological and biochemical evidence, J. Cardiovasc. Pharmacol. 13(3) (1989) 412-20.

[38] A. Ghigo, D. Mika, cAMP/PKA signaling compartmentalization in cardiomyocytes: Lessons from FRET-based biosensors, J. Mol. Cell. Cardiol. 131 (2019) 112-121.

[39] E.J. Tsai, D.A. Kass, Cyclic GMP signaling in cardiovascular pathophysiology and therapeutics, Pharmacol. Ther. 122(3) (2009) 216-38.

[40] F. Hubert, M. Belacel-Ouari, B. Manoury, K. Zhai, V. Domergue-Dupont, P. Mateo, et al., Alteration of vascular reactivity in heart failure: role of phosphodiesterases 3 and 4, Br. J. Pharmacol. 171(23) (2014) 5361-75.

[41] W.E. Knight, S. Chen, Y. Zhang, M. Oikawa, M. Wu, Q. Zhou, et al., PDE1C deficiency antagonizes pathological cardiac remodeling and dysfunction, Proc. Natl. Acad. Sci. U. S. A. 113(45) (2016) E7116-E7125.

[42] T. Hashimoto, G.E. Kim, R.S. Tunin, T. Adesiyun, S. Hsu, R. Nakagawa, et al., Acute Enhancement of Cardiac Function by Phosphodiesterase Type 1 Inhibition, Circulation 138(18) (2018) 1974-1987.

[43] H. Mehel, J. Emons, C. Vettel, K. Wittkopper, D. Seppelt, M. Dewenter, et al., Phosphodiesterase-2 Is Up-Regulated in Human Failing Hearts and Blunts $\beta$-Adrenergic Responses in Cardiomyocytes, J. Am. Coll. Cardiol. 62(17) (2013) 1596-606.

[44] E. Patrucco, M.S. Albergine, L.F. Santana, J.A. Beavo, Phosphodiesterase 8A (PDE8A) regulates excitation-contraction coupling in ventricular myocytes, J. Mol. Cell. Cardiol. 49(2) (2010) 330-3.

[45] J. Jurevicius, R. Fischmeister, cAMP compartmentation is responsible for a local activation of cardiac $\mathrm{Ca}^{2+}$ channels by beta-adrenergic agonists, Proc. Natl. Acad. Sci. U. S. A. 93(1) (1996) 295-9. 
[46] V. Timofeyev, R.E. Myers, H.J. Kim, R.L. Woltz, P. Sirish, J.P. Heiserman, et al., Adenylyl cyclase subtype-specific compartmentalization: differential regulation of L-type $\mathrm{Ca}^{2+}$ current in ventricular myocytes, Circ. Res. 112(12) (2013) 1567-76.

[47] F. Scamps, E. Mayoux, D. Charlemagne, G. Vassort, Calcium current in single cells isolated from normal and hypertrophied rat heart. Effects of $\beta$-adrenergic stimulation, Circ. Res. 67(1) (1990) 199-208.

[48] R. Mukherjee, F.G. Spinale, L-type calcium channel abundance and function with cardiac hypertrophy and failure: a review, J. Mol. Cell. Cardiol. 30(10) (1998) 1899-916.

[49] M. Xu, P. Zhou, S.M. Xu, Y. Liu, X. Feng, S.H. Bai, et al., Intermolecular failure of L-type $\mathrm{Ca}^{2+}$ channel and ryanodine receptor signaling in hypertrophy, PLoS Biol. 5(2) (2007) e21.

[50] F. Schroder, R. Handrock, D.J. Beuckelmann, S. Hirt, R. Hullin, L. Priebe, et al., Increased availability and open probability of single L-type calcium channels from failing compared with nonfailing human ventricle, Circulation 98(10) (1998) 969-76.

[51] J.L. Sanchez-Alonso, A. Bhargava, T. O'Hara, A.V. Glukhov, S. Schobesberger, N. Bhogal, et al., Microdomain-Specific Modulation of L-Type Calcium Channels Leads to Triggered Ventricular Arrhythmia in Heart Failure, Circ. Res. 119(8) (2016) 944-55.

[52] X.Q. Zhang, R.L. Moore, D.L. Tillotson, J.Y. Cheung, Calcium currents in postinfarction rat cardiac myocytes, Am. J. Physiol. 269(6 Pt 1) (1995) C1464-73.

[53] J.Q. He, M.W. Conklin, J.D. Foell, M.R. Wolff, R.A. Haworth, R. Coronado, et al., Reduction in density of transverse tubules and L-type $\mathrm{Ca}^{2+}$ channels in canine tachycardia-induced heart failure, Cardiovasc. Res. 49(2) (2001) 298-307.

[54] X. Chen, V.r. Piacentino, S. Furukawa, B. Goldman, K.B. Margulies, S.R. Houser, L-type $\mathrm{Ca}^{2+}$ channel density and regulation are altered in failing human ventricular myocytes and recover after support with mechanical assist devices, Circ. Res. 91(6) (2002) 517-24.

[55] D.R. Zakhary, C.S. Moravec, R.W. Stewart, M. Bond, Protein kinase A (PKA)-dependent troponin-I phosphorylation and PKA regulatory subunits are decreased in human dilated cardiomyopathy, Circulation 99(4) (1999) 505-10.

[56] Y.S. Han, J. Arroyo, O. Ogut, Human heart failure is accompanied by altered protein kinase A subunit expression and post-translational state, Arch. Biochem. Biophys. 538(1) (2013) 25-33. [57] D.R. Zakhary, C.S. Moravec, M. Bond, Regulation of PKA binding to AKAPs in the heart: alterations in human heart failure, Circulation 101(12) (2000) 1459-64.

[58] T.T. Aye, S. Soni, T.A. van Veen, M.A. van der Heyden, S. Cappadona, A. Varro, et al., Reorganized PKA-AKAP associations in the failing human heart, J. Mol. Cell. Cardiol. 52(2) (2012) 511-8.

[59] J. Neumann, T. Eschenhagen, L.R. Jones, B. Linck, W. Schmitz, H. Scholz, et al., Increased expression of cardiac phosphatases in patients with end-stage heart failure, J. Mol. Cell. Cardiol. 29(1) (1997) 265-72.

[60] M. Yamada, Y. Ikeda, M. Yano, K. Yoshimura, S. Nishino, H. Aoyama, et al., Inhibition of protein phosphatase 1 by inhibitor-2 gene delivery ameliorates heart failure progression in genetic cardiomyopathy, FASEB J. 20(8) (2006) 1197-9.

[61] O.E. Osadchii, A.J. Woodiwiss, G.R. Norton, Contractile responses to selective phosphodiesterase inhibitors following chronic $\beta$-adrenoreceptor activation, Pflugers Arch. 452(2) (2006) 155-63.

[62] S.M. Bryant, C.H. Kong, J. Watson, M.B. Cannell, A.F. James, C.H. Orchard, Altered distribution of $\mathrm{I}_{\mathrm{Ca}}$ impairs $\mathrm{Ca}$ release at the t-tubules of ventricular myocytes from failing hearts, J. Mol. Cell. Cardiol. 86 (2015) 23-31. 
[63] T. Eschenhagen, PDE4 in the human heart - major player or little helper?, Br. J. Pharmacol. 169(3) (2013) 524-7.

[64] C.E. Molina, D.M. Johnson, H. Mehel, R.L. Spatjens, D. Mika, V. Algalarrondo, et al., Interventricular differences in $\beta$-adrenergic responses in the canine heart: role of phosphodiesterases, J Am Heart Assoc 3(3) (2014) e000858.

[65] C.E. Molina, J. Leroy, W. Richter, M. Xie, C. Scheitrum, I.O. Lee, et al., Cyclic adenosine monophosphate phosphodiesterase type 4 protects against atrial arrhythmias, J. Am. Coll. Cardiol. 59(24) (2012) 2182-90.

[66] J.R. Holmes, S.H. Kubo, R.J. Cody, P. Kligfield, Milrinone in congestive heart failure: observations on ambulatory ventricular arrhythmias, Am. Heart J. 110(4) (1985) 800-6.

[67] M. Packer, J.R. Carver, R.J. Rodeheffer, R.J. Ivanhoe, R. DiBianco, S.M. Zeldis, et al., Effect of oral milrinone on mortality in severe chronic heart failure. The PROMISE Study Research Group, N. Engl. J. Med. 325(21) (1991) 1468-75.

[68] J.R. Teerlink, M. Jalaluddin, S. Anderson, M.L. Kukin, E.J. Eichhorn, G. Francis, et al., Ambulatory ventricular arrhythmias in patients with heart failure do not specifically predict an increased risk of sudden death. PROMISE (Prospective Randomized Milrinone Survival Evaluation) Investigators, Circulation 101(1) (2000) 40-6. 
Table 1: Cardiac phenotype of sham-operated (SHAM) and aortic stenosis (CH) rats

\begin{tabular}{|c|c|c|c|c|c|}
\hline Anatomy & SHAM & $\mathbf{N}$ & $\mathbf{C H}$ & $\mathbf{N}$ & $P$-value \\
\hline BW $(g)$ & $325 \pm 10$ & 23 & $324 \pm 17$ & 17 & n.s \\
\hline TL $(\mathbf{c m})$ & $3.51 \pm 0.06$ & 23 & $3.52 \pm 0.05$ & 17 & n.s \\
\hline HW (g) & $1.47 \pm 0.03$ & 23 & $2.15 \pm 0.08$ & 17 & $P<0.001$ \\
\hline HW/BW (mg/g) & $4.60 \pm 0.13$ & 23 & $6.93 \pm 0.47$ & 17 & $P<0.001$ \\
\hline HW/TL (mg/cm) & $422 \pm 9$ & 23 & $614 \pm 28$ & 17 & $P<0.001$ \\
\hline Cell parameters & SHAM & $\mathbf{n}$ & $\mathbf{C H}$ & $\mathbf{n}$ & $P$-value \\
\hline Capacitance (pF) & $209 \pm 8$ & 53 & $274 \pm 18$ & 35 & $P<0.01$ \\
\hline $\mathbf{I}_{\mathrm{Ca}, \mathrm{L}}$ amplitude (pA) & $1395 \pm 77$ & 53 & $1926 \pm 77$ & 35 & $P<0.05$ \\
\hline $\mathbf{I}_{\mathrm{Ca}, \mathrm{L}}$ density $(\mathbf{p A} / \mathbf{p F})$ & $6,9 \pm 0.4$ & 53 & $7.3 \pm 0.7$ & 35 & n.s. \\
\hline
\end{tabular}

All data are expressed as mean \pm S.E.M. Abbreviations used: BW, body weight; TL, tibia length; HW, heart weight; $N$, number of animals in each group; $n$ number of cells in each group. Statistically significant differences between aortic stenosis $(\mathrm{CH})$ and sham-operated (SHAM) rats are indicated with $P$ value; n.s.: not significantly different (Student t-test). 
FIGURE LEGENDS

Figure 1. Cytosolic cAMP response to transient $\beta$-AR stimulation in SHAM and CH cardiomyocytes. Left ventricular myocytes (LVMs) were transduced with Epac2-camps adenovirus and challenged with a brief application of isoprenaline (Iso, $100 \mathrm{nM}, 15 \mathrm{~s}$ ). A, Representative pseudocolor images of the CFP/YFP ratio (reflecting the cytosolic [cAMP]) in a LVM isolated from the heart of a sham-operated (SHAM) rat or a hypertrophied $(\mathrm{CH})$ rat. Images shown were taken before Iso application (baseline), at the maximum of the Iso effect (Iso, $100 \mathrm{nM}$, $15 \mathrm{~s}$ ) and after complete washout of Iso (recovery). Scale bar: $20 \mu \mathrm{m}$. B, Average time course of the CFP/YFP ratio (expressed as percent increase over baseline) following Iso (100 nM, 15s) stimulation in SHAM (black diamonds, $\mathrm{n}=19$ cells from 12 rats) and $\mathrm{CH}$ (white diamonds, $\mathrm{n}=16$ cells from 9 rats) LVMs. Each point represents the mean \pm SEM. C, Maximal increase in the CFP/YFP ratio (in \%) following Iso stimulation in SHAM (black diamonds) and $\mathrm{CH}$ (open diamonds) LVMs. D, Time to reach half maximal increase $\left(t_{1 / 20 n}\right.$, calculated from $\left.t_{0}\right)$ of the CFP/YFP ratio following Iso stimulation in SHAM (black diamonds) and $\mathrm{CH}$ (open diamonds) LVMs. E, Average half decay time ( $\mathrm{t}_{1 / 2 \mathrm{off}}$, calculated as the time required for half maximal decay from $\mathrm{t}_{\text {peak }}$ ) of the CFP/YFP ratio following Iso stimulation in SHAM (black diamonds) and $\mathrm{CH}$ (open diamonds) LVMs. Bars represent the mean \pm SEM. There was no statistically significant difference between SHAM and CH groups (Mann-Whitney test).

Figure 2. Effect of PDE4 inhibition on cytosolic cAMP upon a $\beta$-AR stimulation in LVMs from SHAM and CH rats. LVMs from SHAM and $\mathrm{CH}$ rats were transduced with Epac2-camps adenovirus and challenged with isoprenaline (Iso, $100 \mathrm{nM}, 15 \mathrm{~s}$ ) alone or in the presence of the 
PDE4 inhibitor, Ro 20-1724 (Ro, $10 \mu \mathrm{M})$. A, Average time course of the CFP/YFP ratio (expressed as percent increase over baseline) following Iso pulse stimulation in SHAM LVMs, alone (black diamonds, $\mathrm{n}=15$ cells from 8 rats) or in the presence of Ro (grey squares, $\mathrm{n}=13$ cells from 8 rats). $\mathrm{B}$, Average time course of the CFP/YFP ratio (expressed as percent increase over baseline) following Iso pulse stimulation in CH LVMs alone (white diamonds, $n=15$ cells from 7 rats) or in the presence of Ro (grey squares, $\mathrm{n}=14$ cells from 7 rats). Ro was applied 5 min. before Iso and then maintained throughout the experiments. Each point represents the mean \pm SEM. C, Maximal increase in CFP/YFP in SHAM (black diamonds) and $\mathrm{CH}$ (white diamonds) LVMs upon stimulation with Iso alone or in the presence of Ro. D, Time to reach half maximal increase $\left(\mathrm{t}_{1 / 2 \mathrm{on}}\right)$ of the CFP/YFP ratio following Iso stimulation alone or in the presence of Ro in SHAM (black diamonds) and in $\mathrm{CH}$ (open diamonds) LVMs. E, Half-decay time ( $\left.\mathrm{t}_{1 / 2 \mathrm{off}}\right)$ of the CFP/YFP ratio following Iso stimulation alone or in the presence of Ro in SHAM (black diamonds) and in $\mathrm{CH}$ (open diamonds) LVMs. Bar graphs in C-E represent the mean \pm SEM. In A and $\mathrm{B}, * P<0.05$ indicates the first of the statistically significant difference between Iso and Iso + Ro on the graph. ns: not significant $(P>0.05)$. Two-way, mixed-effects ANOVA followed by Sidak's post-hoc test. In C-E, $* P<005, * * P<0.01, * * * P<0.001$ indicates statistically significant difference between Iso and Iso + Ro; ${ }^{\$ \$} P<0.001$ indicates statistically significant difference between SHAM and $\mathrm{CH}$ LVMs. Two-way ANOVA with Tukey's post-hoc test.

Figure 3. Effect of PDE3 inhibition on cytosolic cAMP upon a $\beta$-AR stimulation in LVMs from SHAM and CH rats. LVMs from SHAM and CH rats were transduced with Epac2-camps adenovirus and challenged with isoprenaline (Iso, $100 \mathrm{nM}, 15 \mathrm{~s}$ ) alone or in the presence of the PDE3 inhibitor, cilostamide (Cil, $1 \mu \mathrm{M})$. A, Average time course of the CFP/YFP ratio (expressed 
as percent increase over baseline) following Iso pulse stimulation in SHAM LVMs, alone (black diamonds, $n=16$ cells from 10 rats) or in the presence of Cil (grey squares, $n=27$ cells from 8 rats). Cil was applied $5 \mathrm{~min}$. before Iso and then maintained throughout the experiments. B, Average time course of the CFP/YFP ratio (expressed as percent increase over baseline) following Iso pulse stimulation in $\mathrm{CH}$ LVMs alone (open diamonds, $\mathrm{n}=16$ cells from 8 rats) or in the presence of Cil (grey squares, $n=19$ cells from 8 rats). Each point represents the mean \pm SEM. C, Maximal increase in CFP/YFP in SHAM (black diamonds) and $\mathrm{CH}$ (white diamonds) LVMs upon stimulation with Iso alone or in the presence of Cil. D, Time to reach half maximal increase $\left(\mathrm{t}_{1 / 2}\right.$ on $)$ of the CFP/YFP ratio following Iso stimulation alone or in the presence of Cil in SHAM (black diamonds) and in $\mathrm{CH}$ (open diamonds) LVMs. E, Half-decay time $\left(\mathrm{t}_{1 / 2 \mathrm{off}}\right)$ of the CFP/YFP ratio following Iso stimulation alone or in the presence of Cil in SHAM (black diamonds) and in $\mathrm{CH}$ (open diamonds) LVMs. Bar graphs in C-E represent the mean \pm SEM. $* * * P<0.001$, In $\mathrm{B}, * P<0.05$ indicates the first of the statistically significant difference between Iso and Iso + Cil on the graph. ns: not significant $(P>0.05)$. Two-way, mixed-effects ANOVA followed by Sidak's post-hoc test. In CE, $* * * P<0.001$ indicates statistically significant difference between Iso and Iso+Cil; ${ }^{\$} P<0.01$ indicates statistically significant difference between SHAM and CH LVMs. Two-way ANOVA with Tukey's post-hoc test.

\section{Figure 4. Regulation of $I_{C a, L}$ by $\beta$-AR stimulation in SHAM and CH cardiomyocytes.}

A, Representative current traces of macroscopic $I_{C a, L}$ elicited by repetitive (every 8 s.) depolarization at $0 \mathrm{mV}$ during $400 \mathrm{~ms}$ from a holding potential of -50 mV in a SHAM (3 upper traces) and in a CH LVM (3 lower traces). These traces were recorded (a) immediately before pulse stimulation with isoprenaline (Iso, $100 \mathrm{nM}, 15 \mathrm{~s}$ ), (b) at the maximum of the Iso stimulation, 
and (c) after complete recovery of $I_{\mathrm{Ca}, \mathrm{L}}$ to baseline values . B Average time course of $I_{C a, L}$ amplitude expressed as \% increase over baseline following Iso (100 nM, $15 \mathrm{~s})$ stimulation in SHAM (black diamonds, $\mathrm{n}=27$ cells from 13 rats) and $\mathrm{CH}$ (white diamonds, $\mathrm{n}=17$ cells from 7 rats) LVMs. Each point represents the mean \pm SEM. C, Maximal increase in $I_{\mathrm{Ca}, \mathrm{L}}$ elicited by Iso pulse stimulation in SHAM (black diamonds) and $\mathrm{CH}$ (white diamonds) LVMs. D, Average time to reach half maximal increase $\left(\mathrm{t}_{1 / 20 n}\right)$ of $I_{\mathrm{Ca}, \mathrm{L}}$ following Iso stimulation in SHAM (black diamonds) and $\mathrm{CH}$ (white diamonds) LVMs. E, Average half decay time ( $\mathrm{t}_{1 / 2 \mathrm{off}}$, calculated as the time required for half maximal decay from $\mathrm{t}_{\mathrm{peak}}$ ) of $I_{\mathrm{Ca}, \mathrm{L}}$ following Iso stimulation in SHAM (black diamonds) and $\mathrm{CH}$ (white diamonds) LVMs. B and C show individual measures and the mean \pm SEM. Statistically significant difference between SHAM and CH LVMs is indicated as *** $P<0.001$ (Student t-test).

\section{Figure 5. Effect of PDE4 inhibition on $I_{\mathrm{Ca}, \mathrm{L}}$ upon transient $\beta$-AR stimulation in SHAM and} CH cardiomyocytes. A, Average time course of $I_{\mathrm{Ca}, \mathrm{L}}$ amplitude (expressed as \% increase over baseline) in SHAM LVMs stimulated by Iso (100 nM, 15 s) alone (black diamonds, $\mathrm{n}=16$ cells from 6 rats) or in the presence of the PDE4 inhibitor, Ro 20-1724 (Ro, $10 \mu \mathrm{M}$ grey squares, $\mathrm{n}=9$ cells from 6 rats). B, Average time course of $I_{\mathrm{Ca}, \mathrm{L}}$ amplitude (expressed as $\%$ increase over baseline) following Iso pulse stimulation in CH LVMs alone (white diamonds, $\mathrm{n}=10$ cells from 3 rats) or in the presence of $10 \mu \mathrm{M}$ Ro (grey squares, $\mathrm{n}=9$ cells from 3 rats). Ro was applied 5 min. before Iso and then maintained throughout the experiments. Each point represents the mean \pm SEM. C, Maximal increase in $I_{\mathrm{Ca}, \mathrm{L}}$ elicited by Iso pulse alone or in the presence of Ro in SHAM (black diamonds) and $\mathrm{CH}$ (white diamonds) LVMs. D, Time to reach half maximal increase $\left(\mathrm{t}_{1 / 2 \mathrm{on}}\right)$ of $I_{\mathrm{Ca}, \mathrm{L}}$ following Iso stimulation alone or in the presence of Ro in SHAM (black diamonds) and in $\mathrm{CH}$ (open diamonds) LVMs. E, Half-decay time ( $\mathrm{t}_{1 / 2 \text { off }}$ ) of $I_{\mathrm{Ca}, \mathrm{L}}$ amplitude following Iso 
stimulation alone or in the presence of $10 \mu \mathrm{M}$ Ro in SHAM (black diamonds) and in $\mathrm{CH}$ (open diamonds) LVMs. For both SHAM and $\mathrm{CH}$ groups, reference cells stimulated with Iso alone represent a subset of the cells presented in Figure 4, which corresponds to cells of the same dissociation as cells in which the condition Iso+Ro was tested. Bar graphs in C-E represent the mean \pm SEM. In C-E, $* P<005, * * P<0.01$, indicate statistically significant differences between Iso and Iso + Ro. Two-way ANOVA with Tukey's post-hoc test.

Figure 6. Effect of PDE3 inhibition on $I_{\mathrm{Ca}, \mathrm{L}}$ upon transient $\beta$-AR stimulation in SHAM and CH cardiomyocytes. A, Average time course of $I_{\mathrm{Ca}, \mathrm{L}}$ amplitude (expressed as $\%$ increase over baseline) following Iso pulse stimulation in SHAM LVMs, alone (black diamonds, $\mathrm{n}=15$ cells from 8 rats) or in the presence of the PDE3 inhibitor, cilostamide (Cil, $1 \mu \mathrm{M}$, grey squares, $\mathrm{n}=17$ cells from 8 rats). B, Average time course of $I_{\mathrm{Ca}, \mathrm{L}}$ amplitude (expressed as percent increase over baseline) following Iso pulse stimulation in CH LVMs alone (white diamonds, $\mathrm{n}=16$ cells from 7 rats) or in the presence of Cil (grey squares, $n=9$ cells from 6 rats). Cil was applied 5 min. before Iso and then maintained throughout the experiments. Each point represents the mean \pm SEM. C, Maximal increase in $I_{\mathrm{Ca}, \mathrm{L}}$ elicited by Iso pulse alone or in the presence of Cil in SHAM (black diamonds) and $\mathrm{CH}$ (white diamonds) LVMs. D, Time to reach half maximal increase $\left(\mathrm{t}_{1 / 2 \mathrm{on}}\right)$ of $I_{\mathrm{Ca}, \mathrm{L}}$ following Iso stimulation alone or in the presence of Cil in SHAM (black diamonds) and in $\mathrm{CH}$ (open diamonds) LVMs. E, Half-decay time ( $\left.\mathrm{t}_{1 / 2 \mathrm{off}}\right)$ of $I_{\mathrm{Ca}, \mathrm{L}}$ amplitude following Iso stimulation alone or in the presence of $1 \mu \mathrm{M}$ Cil in SHAM (black diamonds) and in $\mathrm{CH}$ (open diamonds) LVMs. For both SHAM and $\mathrm{CH}$ groups, reference cells stimulated with Iso alone represent a subset of the cells presented in Figure 4, which corresponds to cells of the same dissociation as cells in which the condition Iso+Cil was tested. Bar graphs in C-E represent the mean \pm SEM. In 
C-E, ${ }^{*} P<0.05$ indicates statistically significant difference between Iso and Iso $+\mathrm{Cil} ;{ }^{\$} P<0.01$ indicates statistically significant difference between SHAM and CH LVMs. Two-way ANOVA with Tukey's post-hoc test.

Figure 7. Comparative kinetics of cytosolic cAMP and $I_{\mathrm{Ca}, \mathrm{L}}$ responses to $\beta$-AR stimulation alone or in combination with PDE3 or PDE4 inhibitor in SHAM and CH LVMs. The effect of Iso (100 nM, 15s) alone or in the presence of cilostamide (Cil, $1 \mu \mathrm{M}$ ) or Ro-201724 (Ro $10 \mu \mathrm{M}$ ) on the $\mathrm{t}_{1 / 2 \text { on }}(\mathrm{A}, \mathrm{C}$ and $\mathrm{E})$ and $\mathrm{t}_{1 / 2 \text { off }}(\mathrm{B}, \mathrm{D}$ and $\mathrm{F})$ of cytosolic cAMP and $I_{\mathrm{Ca}, \mathrm{L}}$ measured in Fig. 2, 3 and 5 in SHAM (black symbols) and $\mathrm{CH}$ (white symbols) LVMs is recapitulated. $\mathrm{t}_{1 / 20 n}$ is calculated as the time required for half maximal increase from $t_{0}$ while $t_{1 / 2 \text { off }}$ is calculated as the time required for half maximal decay from $\mathrm{t}_{\text {peak. }}$. Individual measure and the mean $\pm \mathrm{SEM}$ are shown. Statistically significant differences between SHAM and $\mathrm{CH}$ are indicated as $* P<0.05, * * * P<0.001$. Statistically significant kinetic differences between cytosolic cAMP (FRET) and $I_{\mathrm{Ca}, \mathrm{L}}$ in SHAM are indicated as ${ }^{\$} P<0.05 ;{ }^{\$ \$} P<0.001$. Statistically significant kinetic differences between cytosolic cAMP (FRET) and $I_{\mathrm{Ca}, \mathrm{L}}$ in $\mathrm{CH}$ are indicated as ${ }^{\#} P<0.05,{ }^{\# \#} P<0.01 ;{ }^{\# \# \#} P<0.001$. Two-way ANOVA with Sidak's multiple comparisons test.

Figure 8. Proposed contribution of PDE3 and PDE4 to the termination of $\beta$-AR responses in normal and hypertrophied cardiomyocytes. In normal myocytes, PDE4 is predominant for the regulation of cytosolic cAMP and L-type $\mathrm{Ca}^{2+}$ current $\left(I_{\mathrm{Ca}, \mathrm{L}}\right)$ upon short $\beta$-AR stimulation by isoprenaline (Iso). In hypertrophied myocytes, both PDE3 and PDE4 are decreased [30] and contribute to regulation of $\beta$-AR cAMP signals in the cytosolic compartment. In the vicinity of L- 
type $\mathrm{Ca}^{2+}$ channels, PDE4 is strongly decreased so that PDE3 is required for recovery of $I_{\mathrm{Ca}, \mathrm{L}}$ from $\beta$-AR stimulation (see text for details). PM, plasma membrane. 
A

\section{Baseline \\ Iso \\ Recovery \\ B}

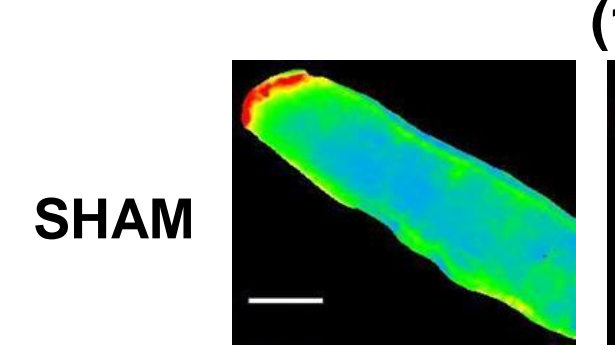
(100 nM, 15 s)

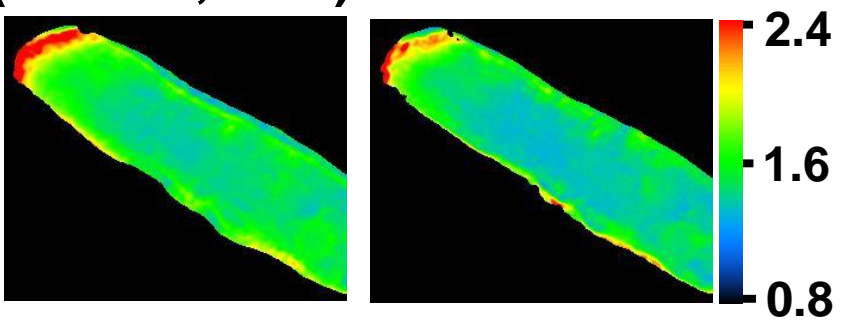

CH
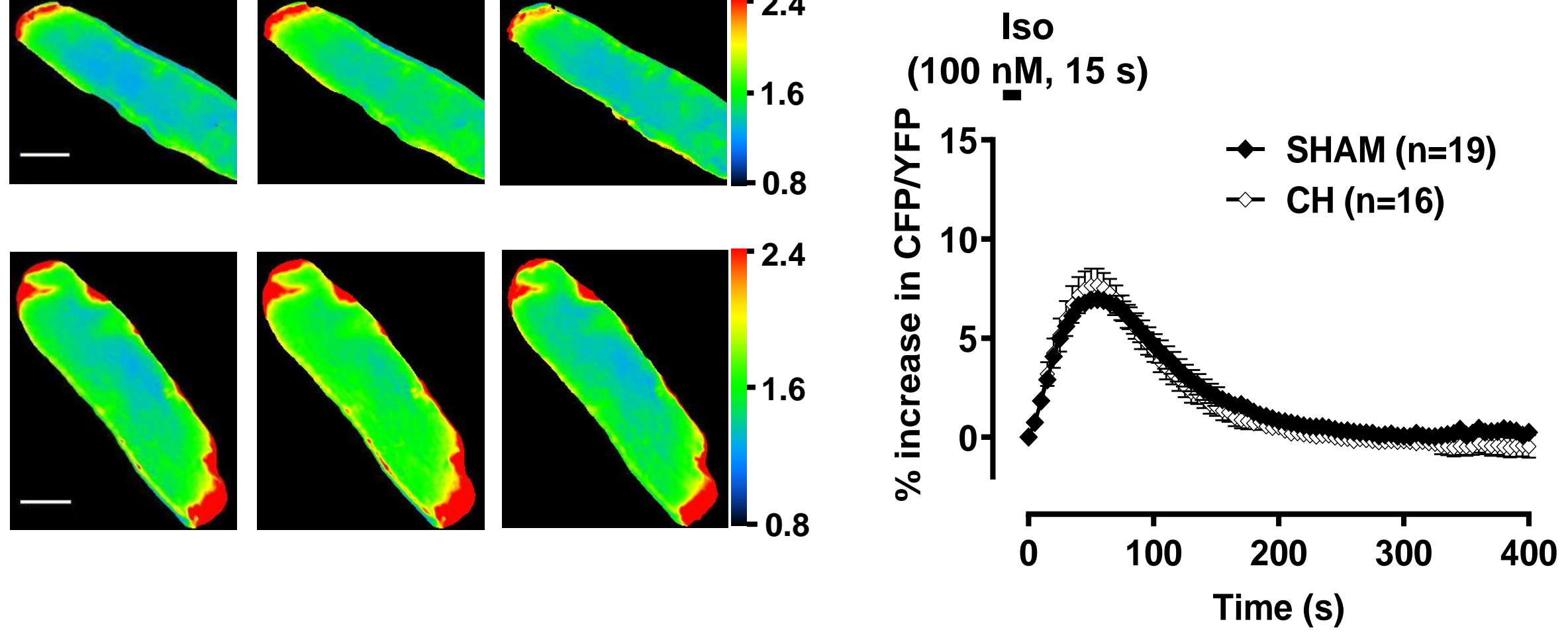

C

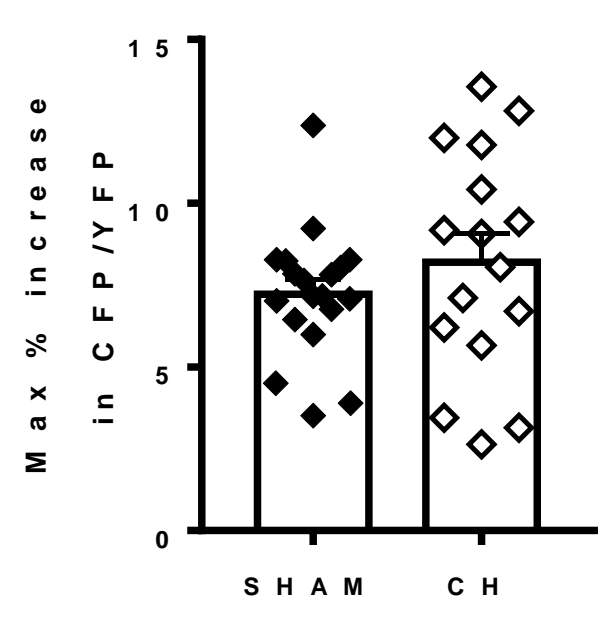

D

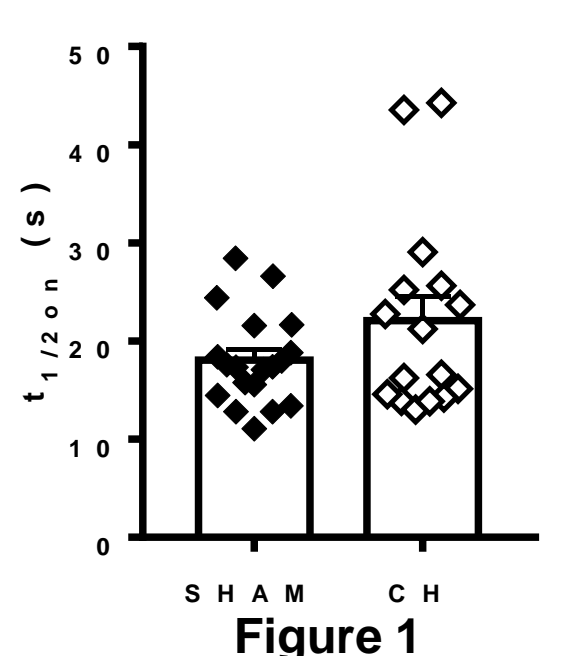

E

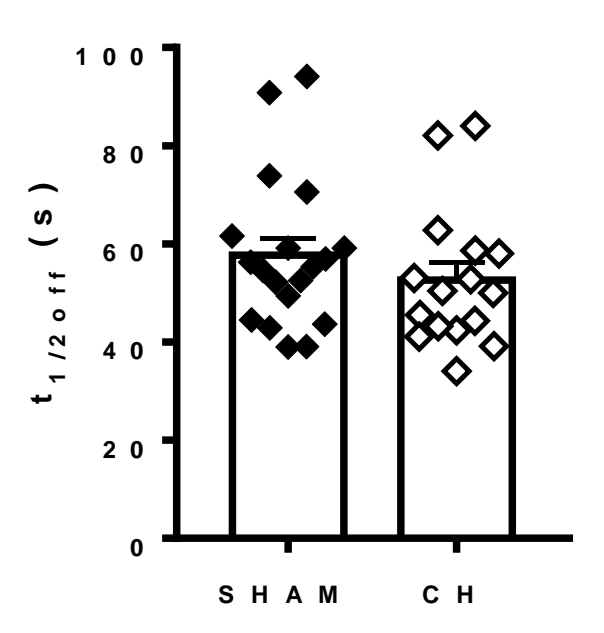

Figure 1 
A

SHAM

Iso

(100 nM, $15 \mathrm{~s}$ )

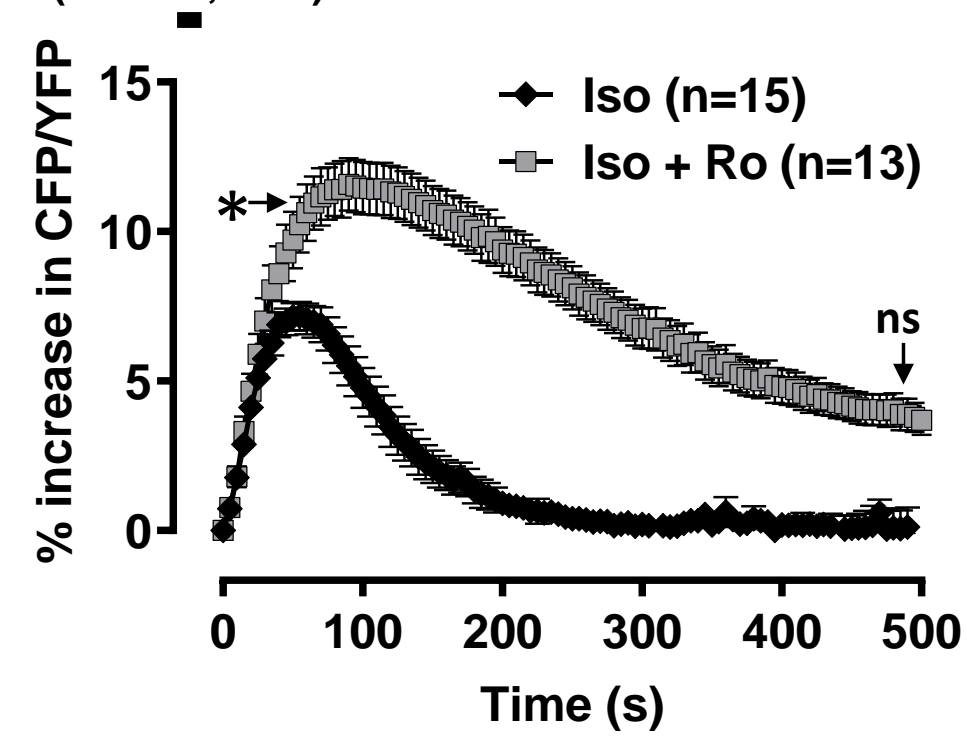

C

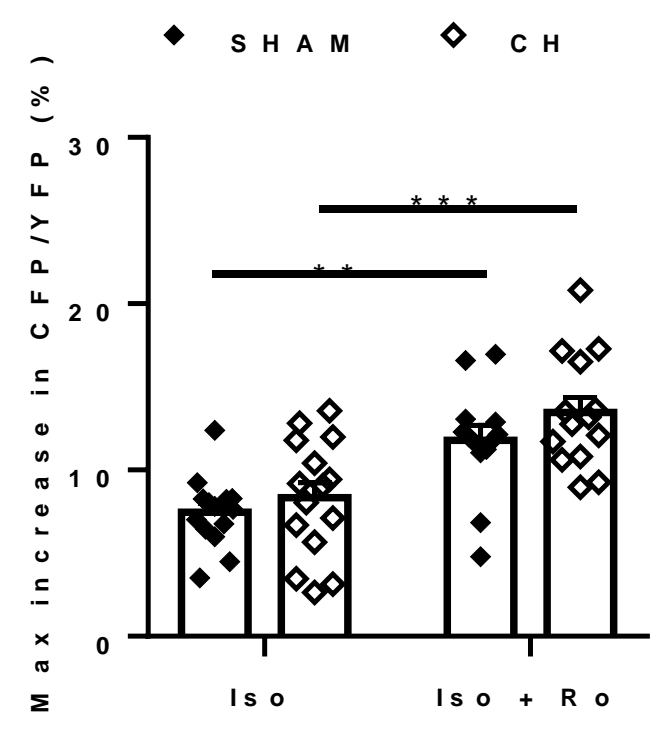

D

- Sham

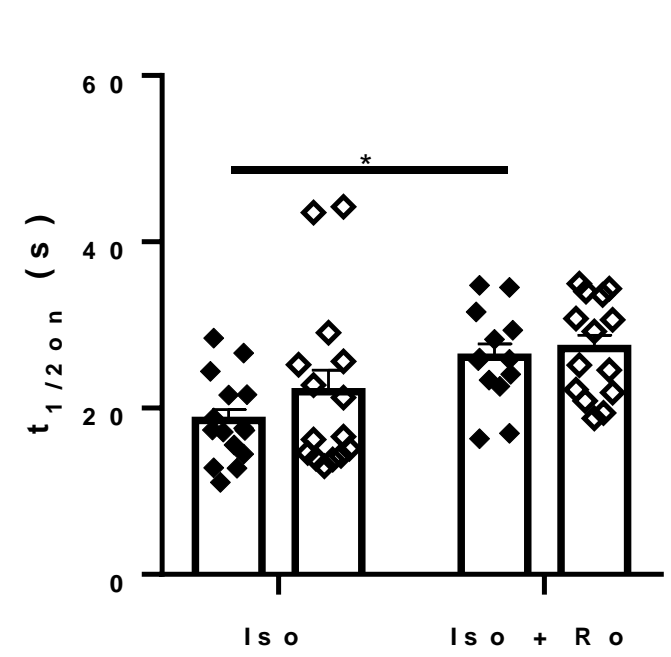

Figure 2

$$
\begin{gathered}
\text { Iso } \\
(100 \mathrm{nM}, 15 \mathrm{~s})
\end{gathered}
$$

CH

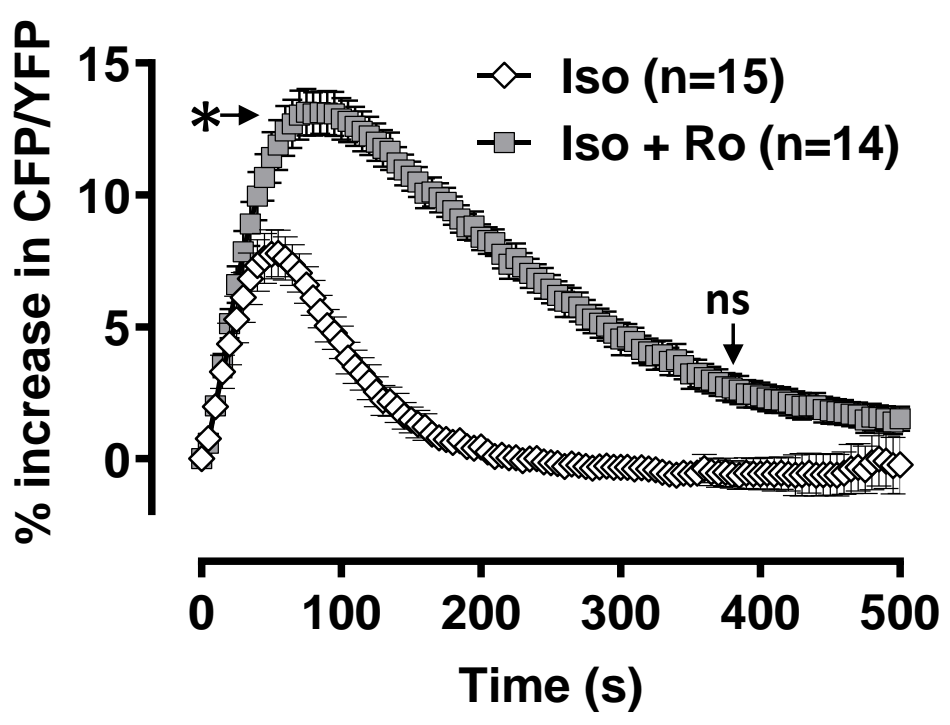

E

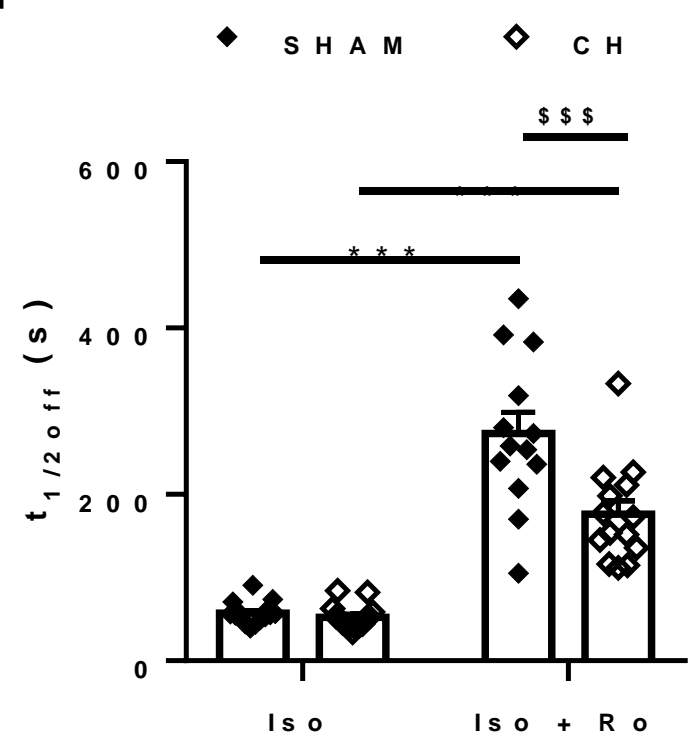


A

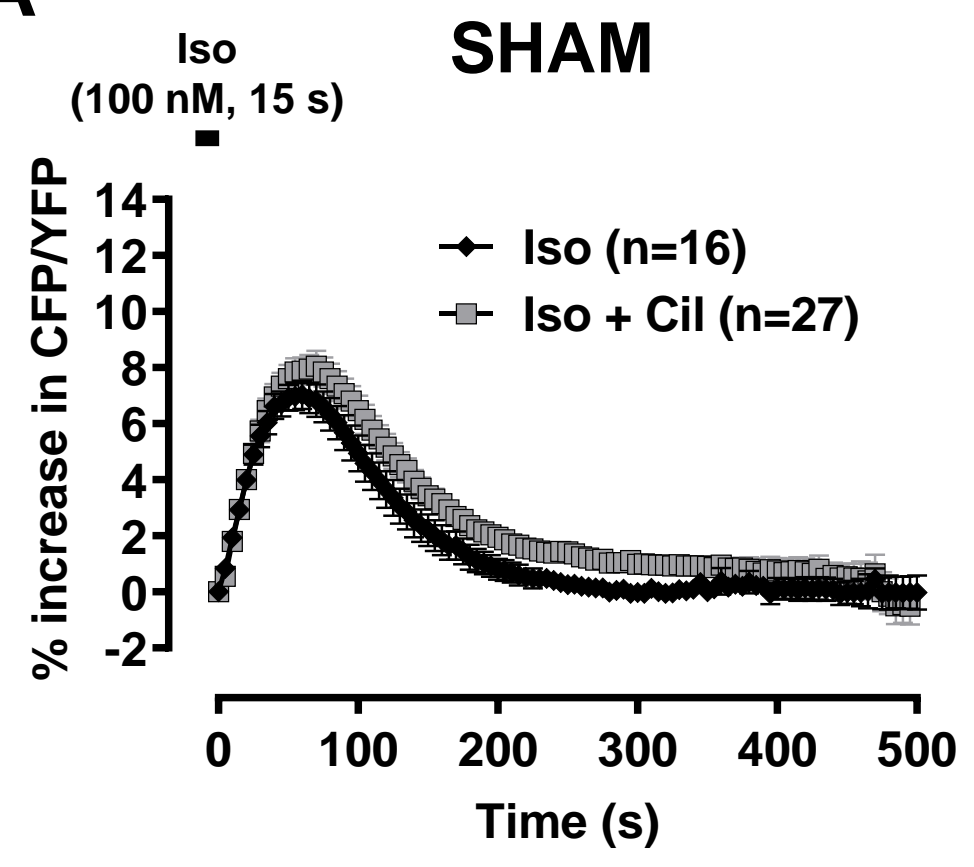

B
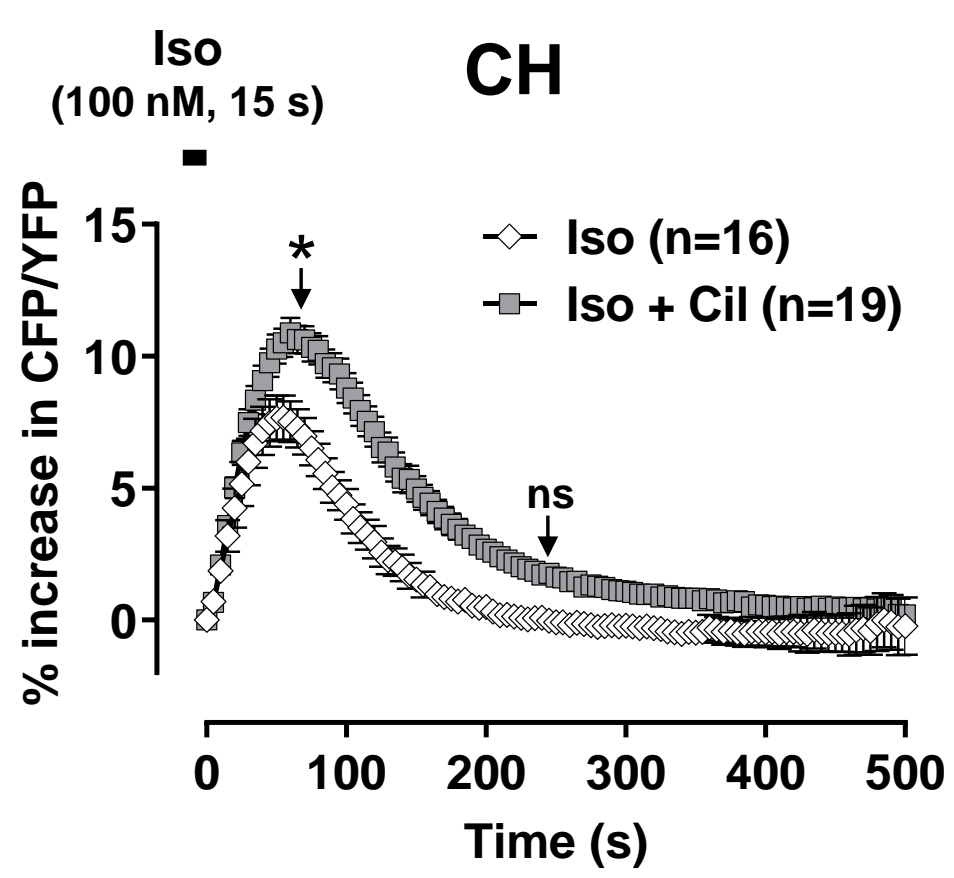

E
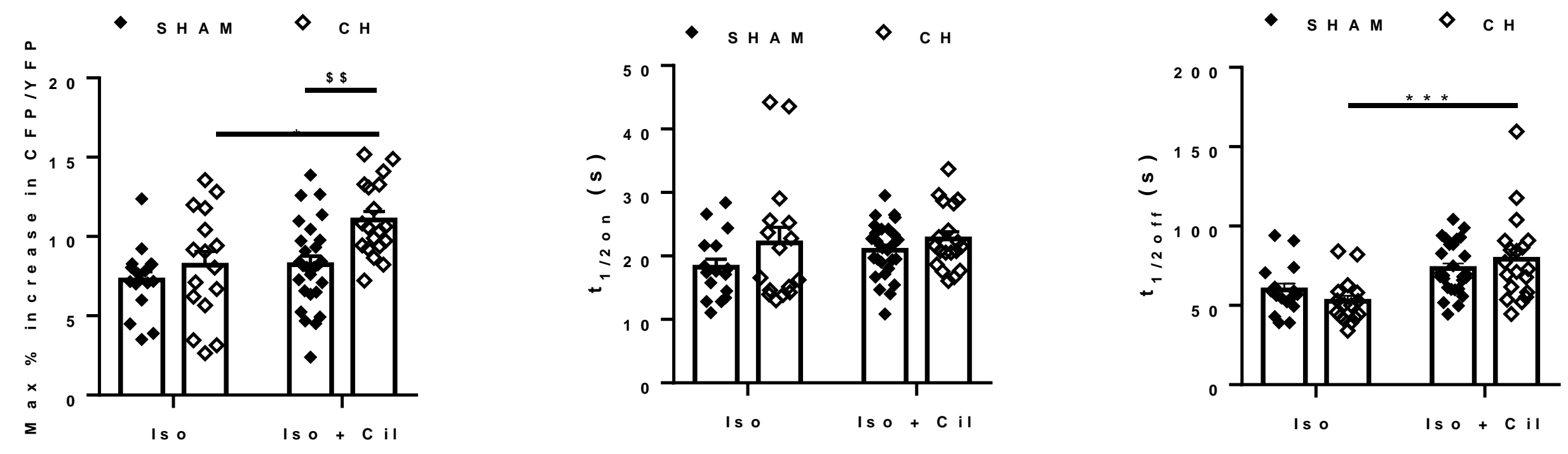

Figure 3 
A
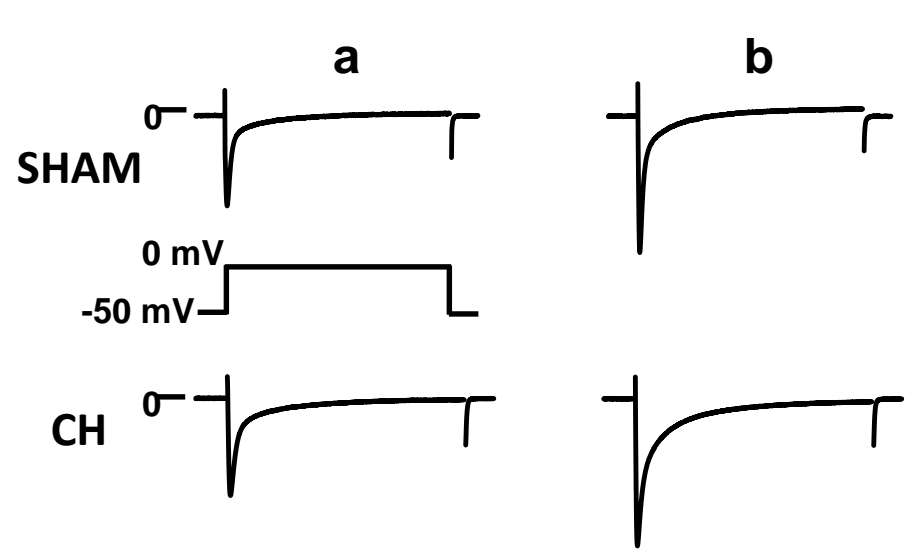

C

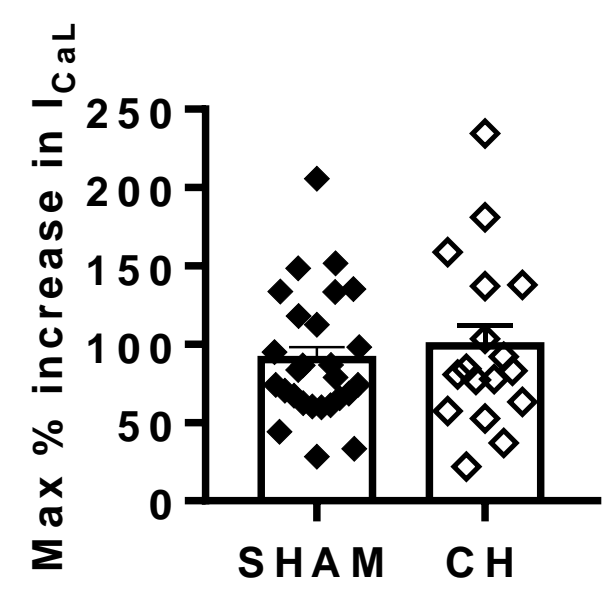

B

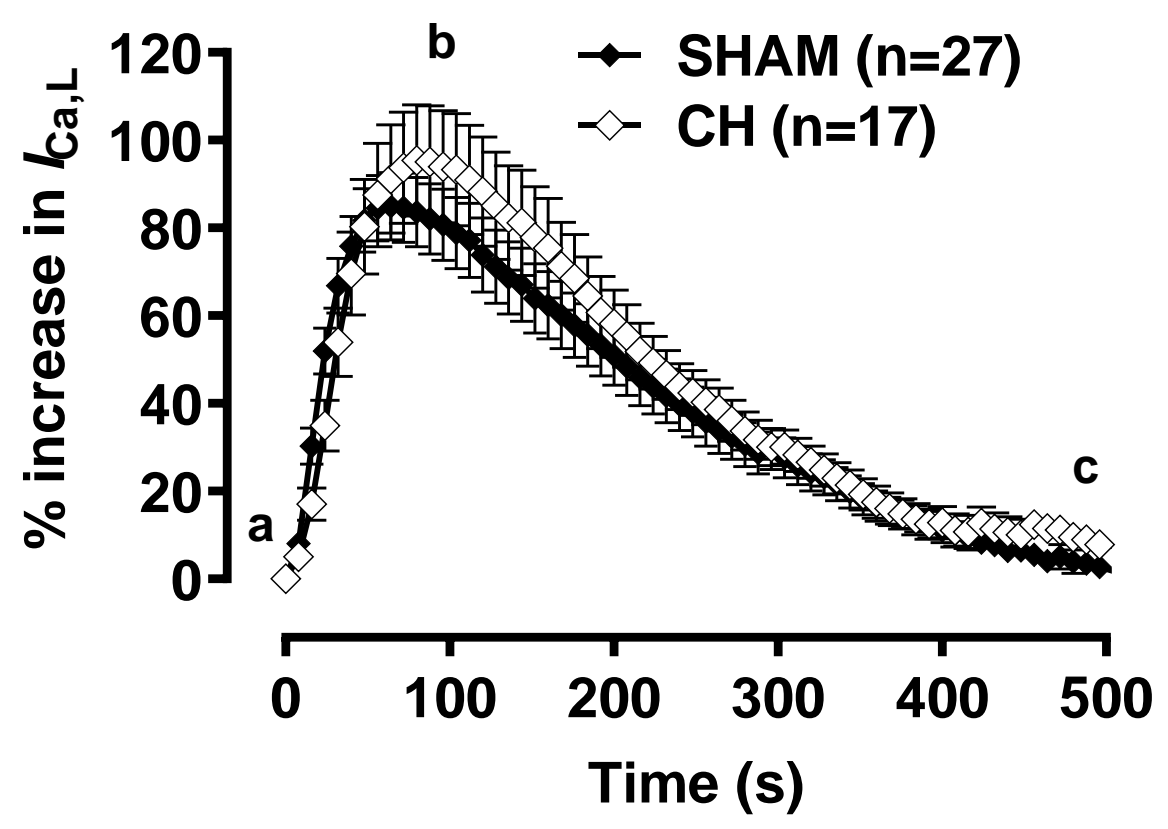

E

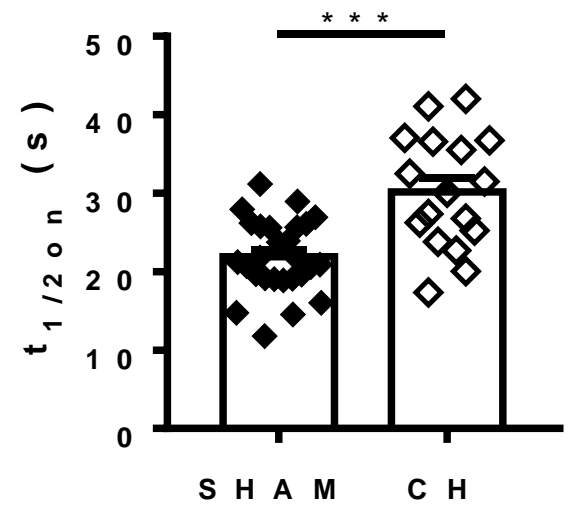

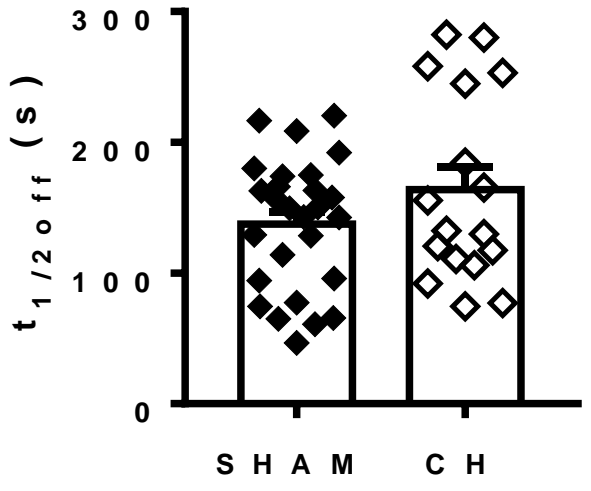


A Iso SHAM

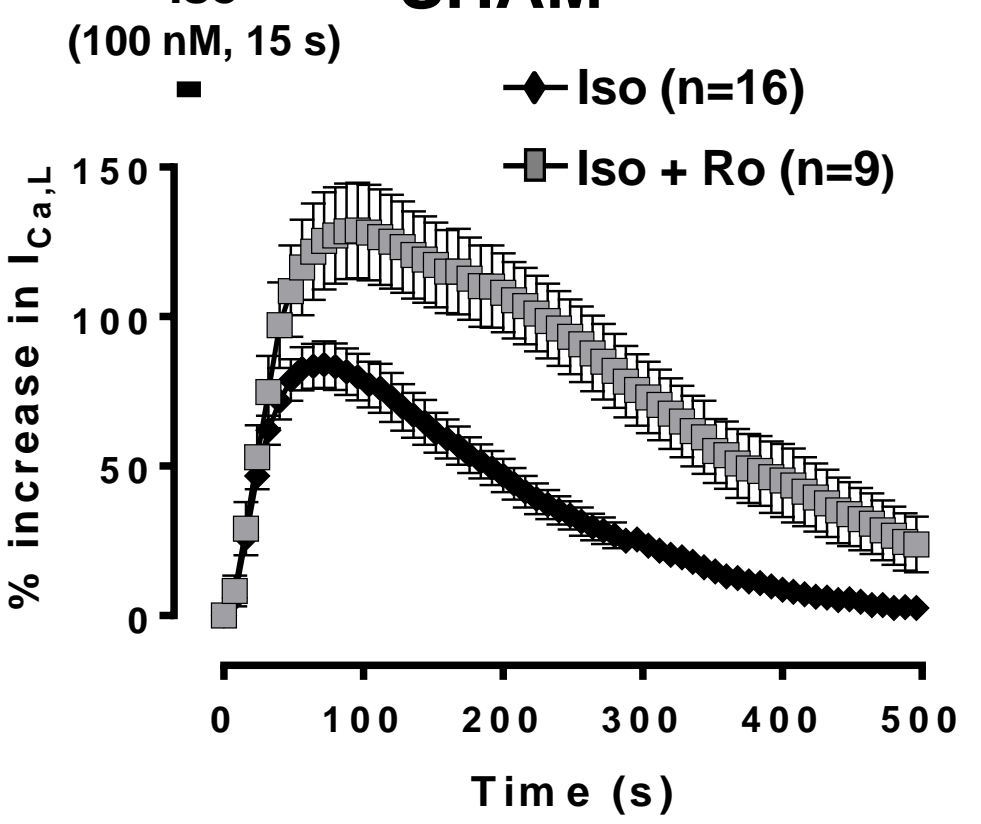

B

\section{Iso}

(100 nM, 15 s)

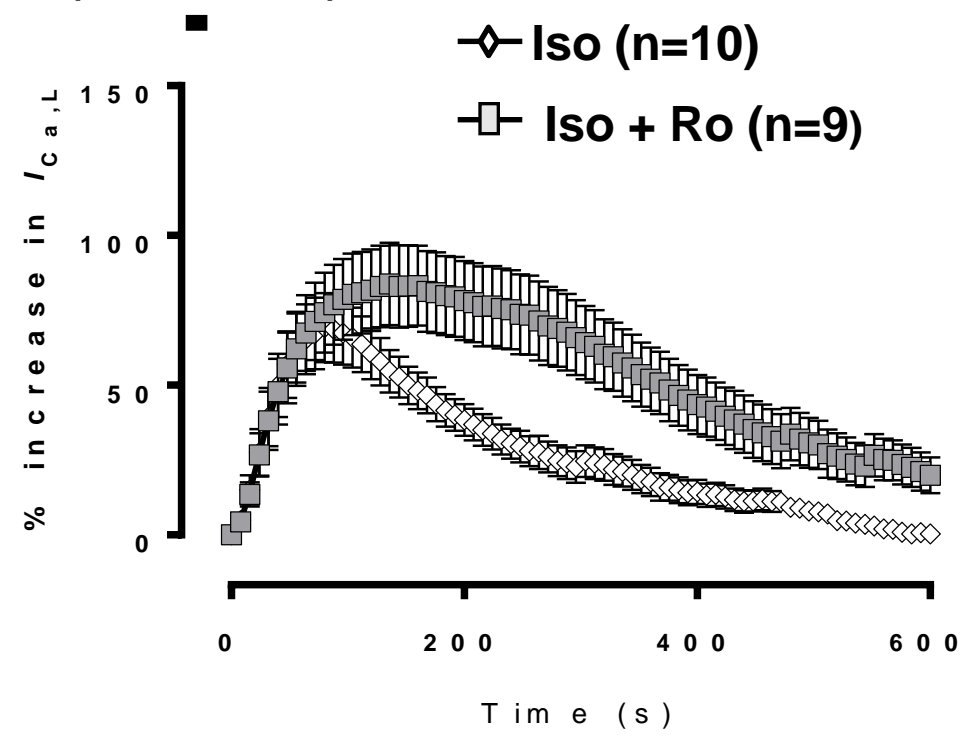

E

\section{$\mathrm{CH}$}

-Iso $(n=10)$

$\checkmark-$ Iso + Ro (n=9)

Tim e (s) $\diamond \mathrm{SHAM} \diamond \mathrm{CH}$

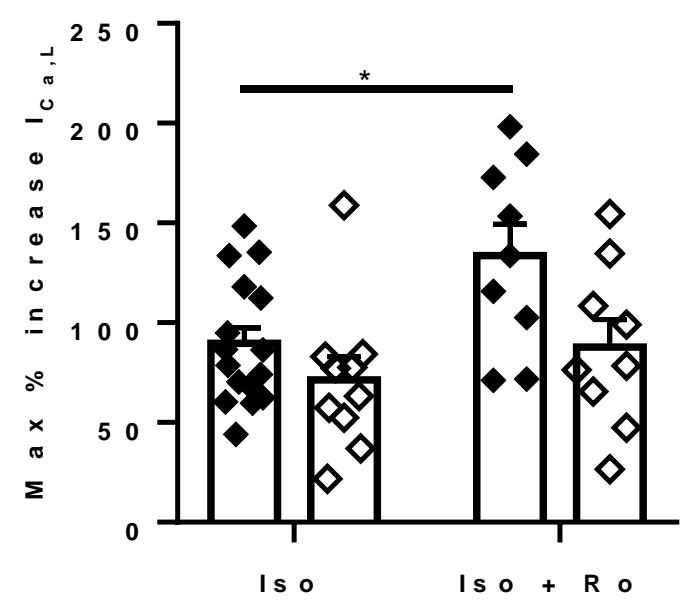

D

$\diamond$ SHAM $\diamond \mathrm{CH}$

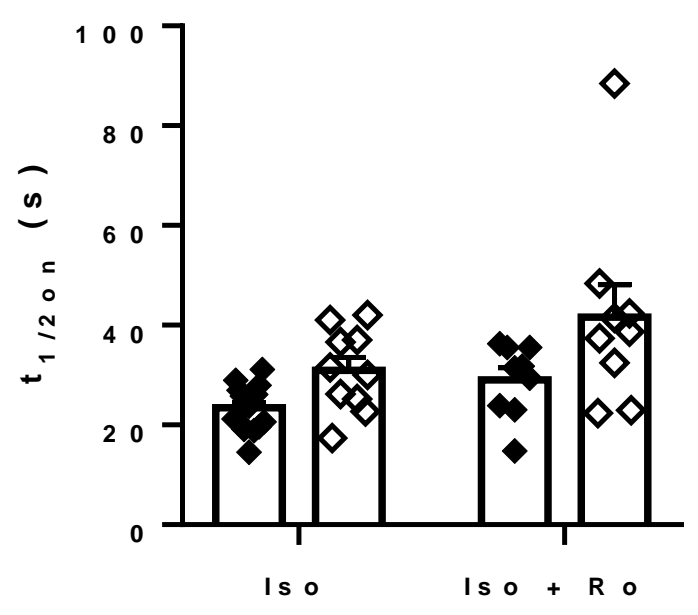

Figure 5

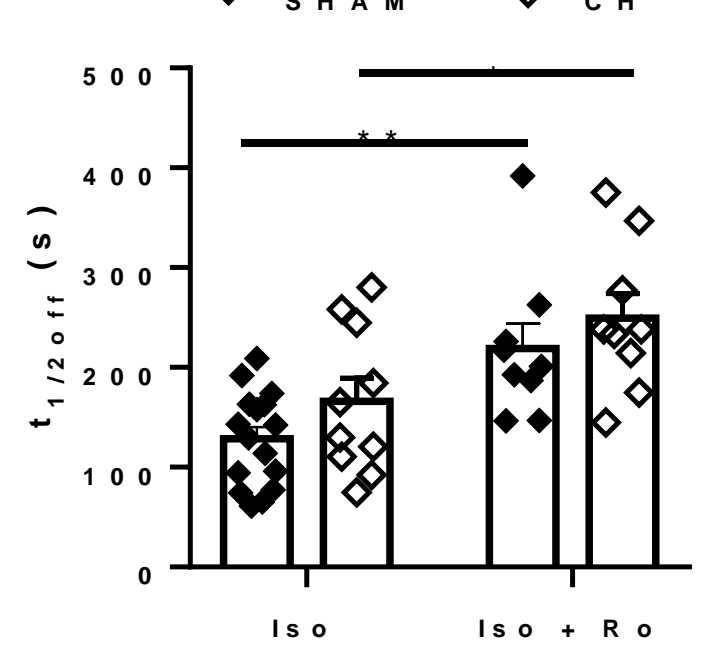


A

Iso

(100 nM, $15 \mathrm{~s}$ )

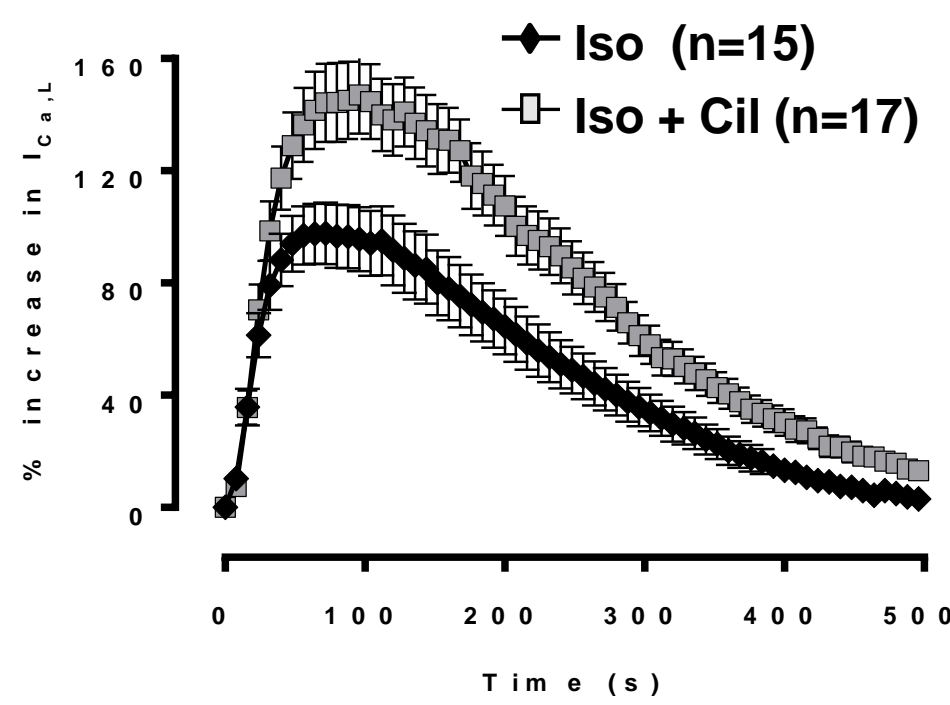

Iso

(100 nM, $15 \mathrm{~s}$ )

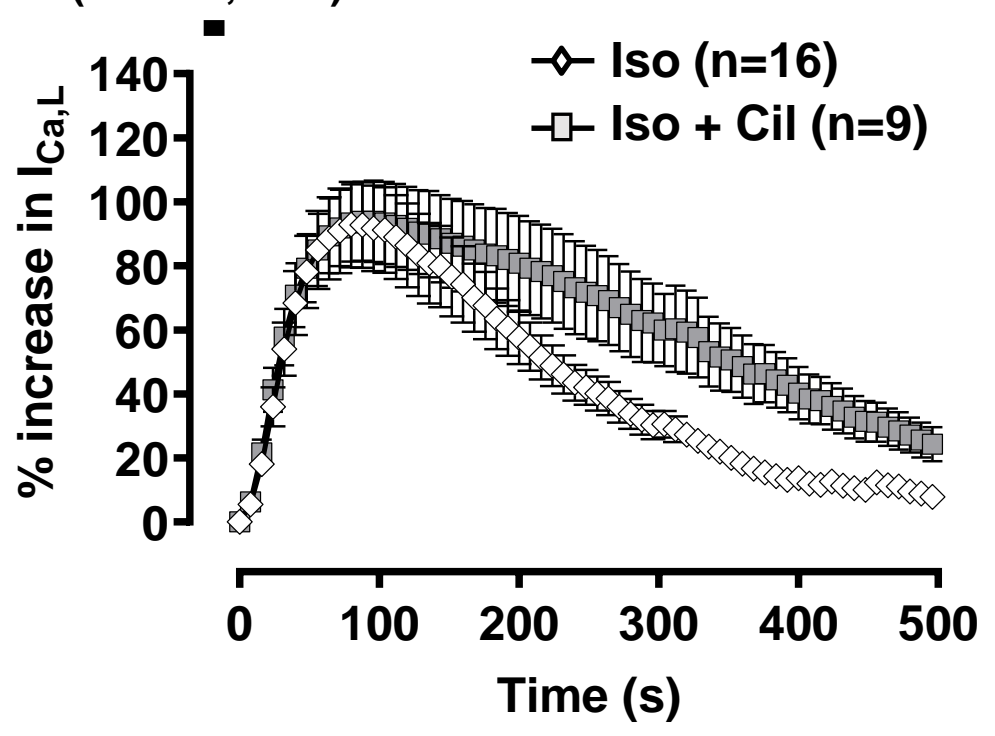

E $\diamond$ SHAM $\diamond$ CH

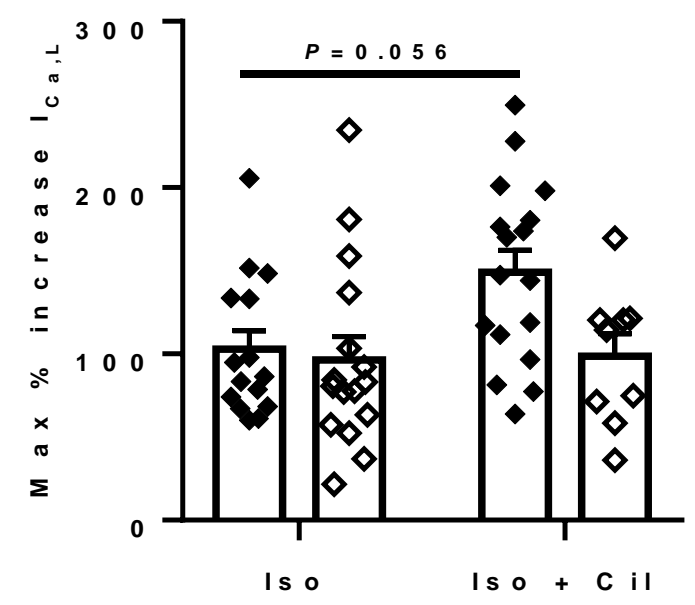

D

$\bullet$ SHAM $\quad$ CH

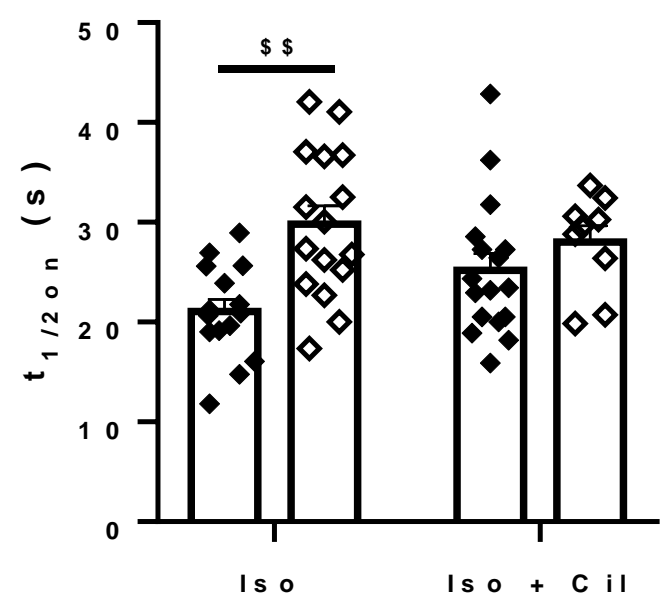

Figure 6

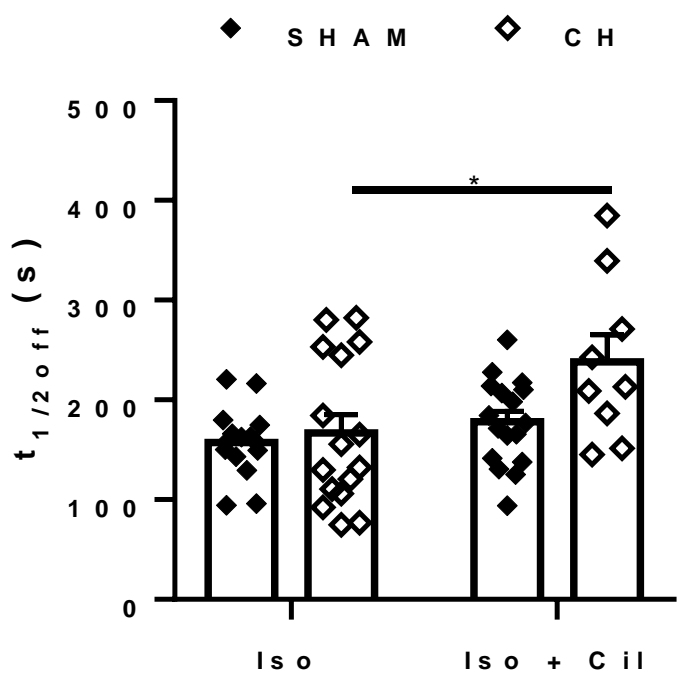




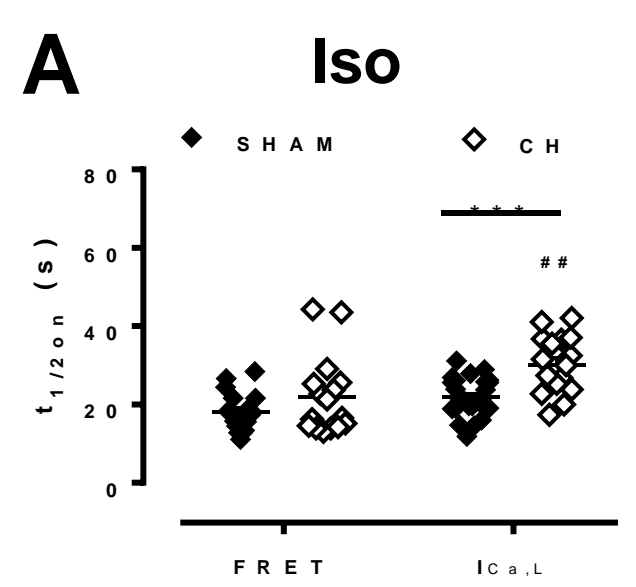

B

\section{Iso}

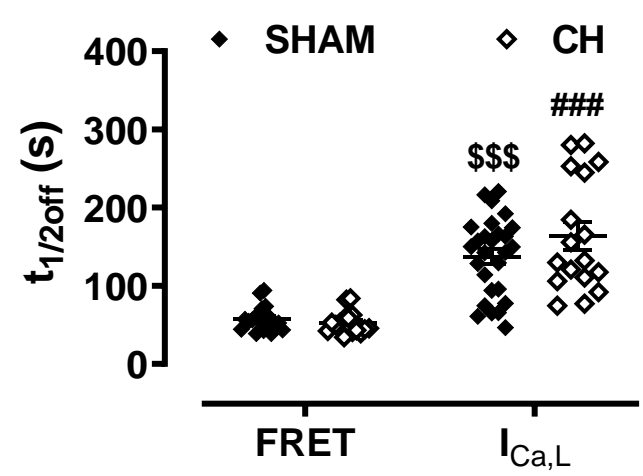

C IsO + Ro

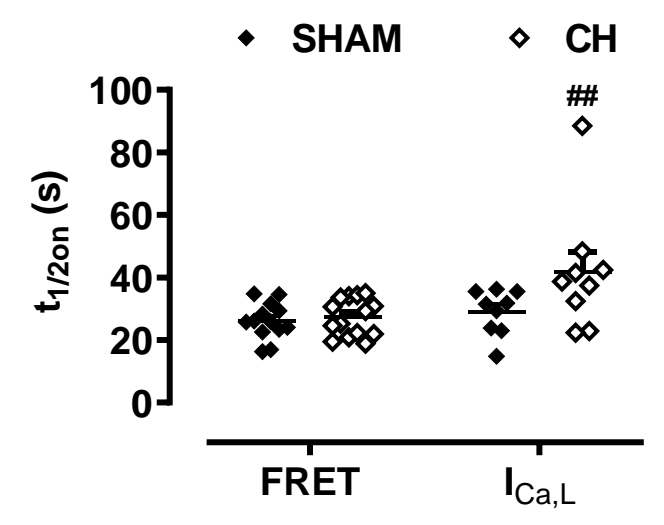

D Iso + Ro
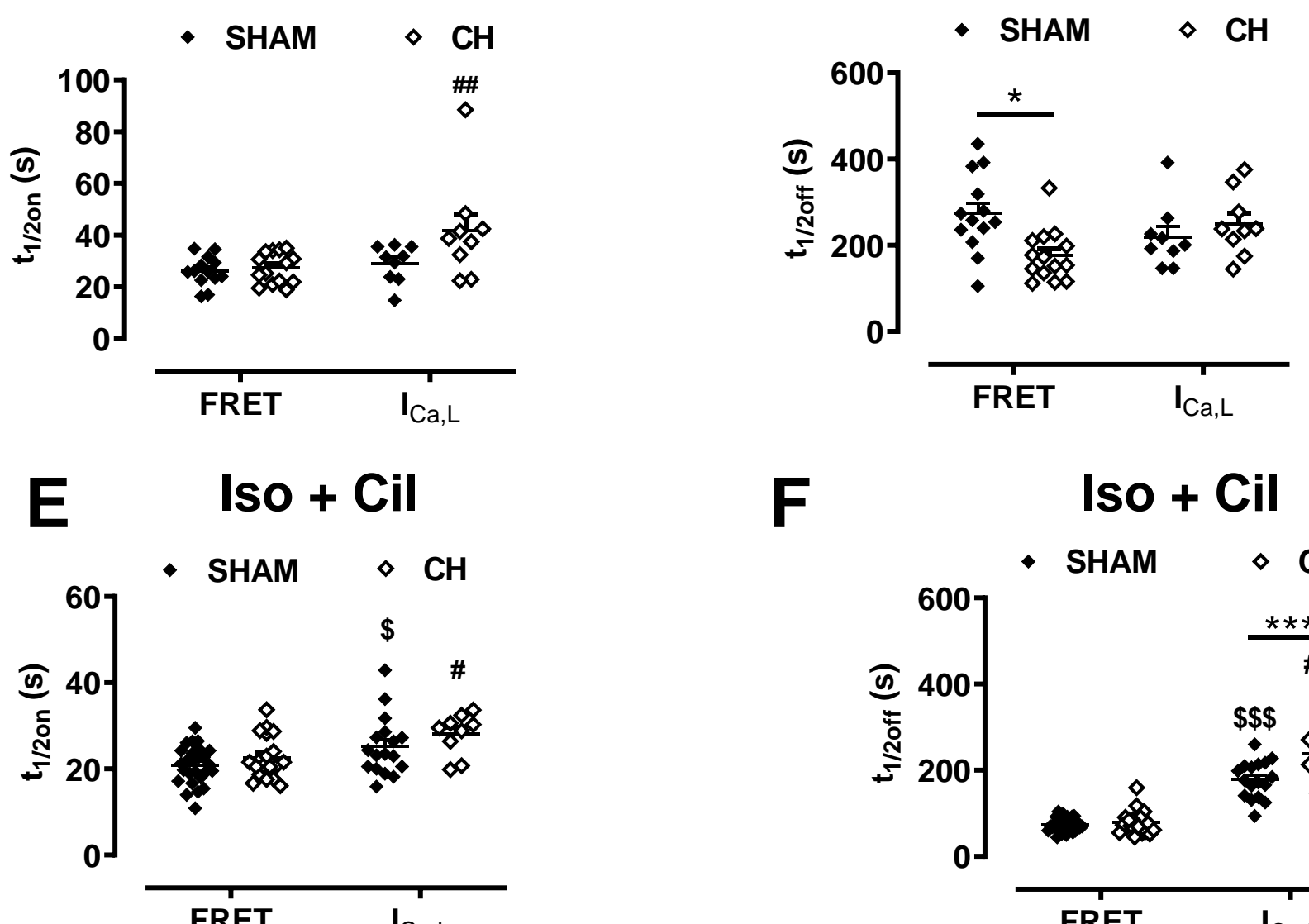

F

Figure 7

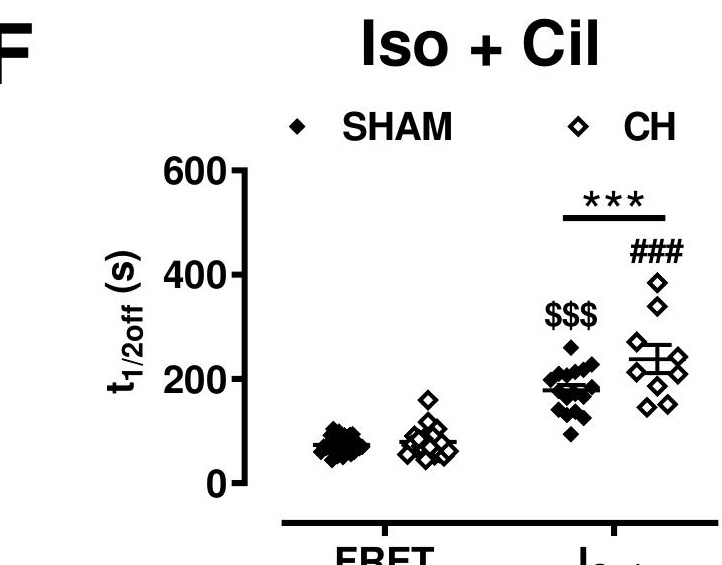




\section{NORMAL MYOCYTE}

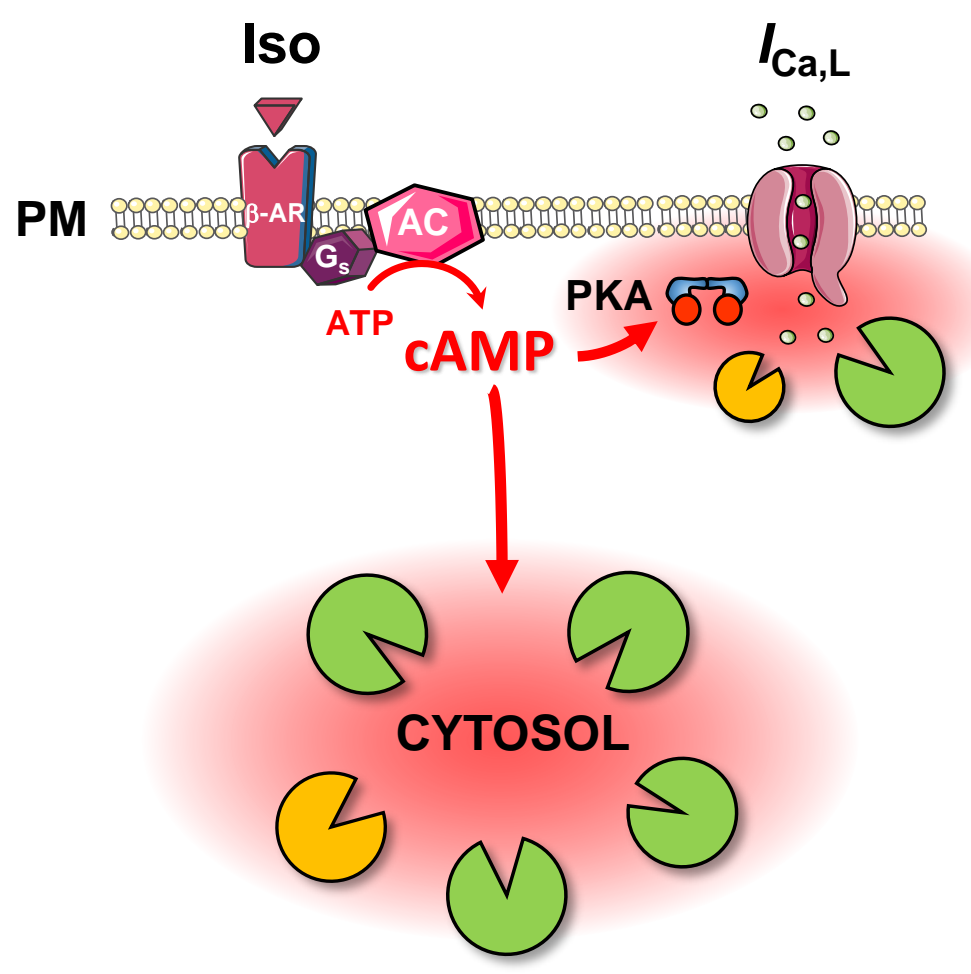

\section{HYPERTROPHIED MYOCYTE}

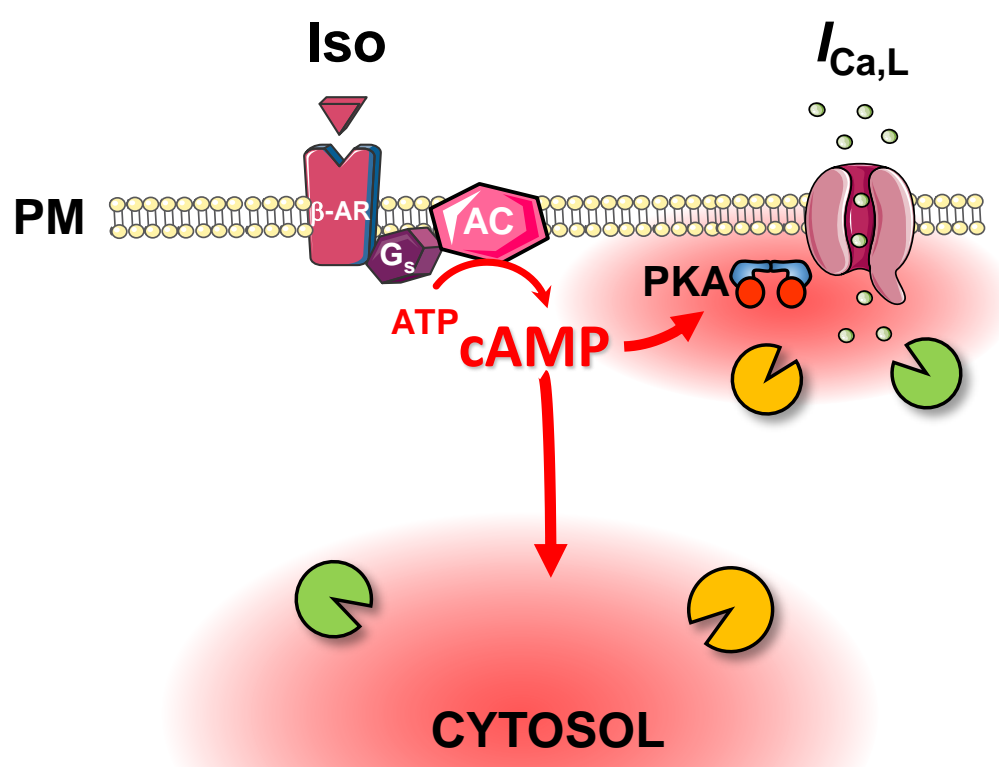

(v)

ß PDE3 3 PDE4

Figure 8 